\title{
Appraisal of geochemical composition and hydrodynamic sorting of the river suspended material: Application of time-integrated suspended sediment sampler in a medium-sized river (the Sava River catchment)
}

Mavro Lučića ${ }^{a}$ Nevenka Mikac ${ }^{a}$, Niko Bačića ${ }^{a}$ Neda Vdović ${ }^{a^{*}}$

${ }^{a}$ Division for Marine and Environmental Research, Ruđer Bošković Institute, Bijenička cesta 54, 10000 Zagreb, Croatia

Mavro.Lucic@irb.hr, Nevenka.Mikac@irb.hr, Niko.Bacic@irb.hr

*corresponding author, Neda.Vdovic@irb.hr

\section{ABSTRACT}

1 The suspended particulate matter (SPM) carried by the rivers shows a wide range of particle

2 size classes, mineralogical and chemical compositions and is mainly influenced by

3 hydrodynamic sorting and provenance during the transport. Here, we have investigated the

4 composition of the SPM in the Sava River and its tributaries (Ljubljanica, Savinja and

5 Krapina) using a time-integrated mass flux sampler (TIMS). The representativeness of

6 material collected by TIMS was evaluated comparing fine-grained sediments, single-point

7 SPM and SPM collected using a shallow and deep-positioned sampler. The main results

8 have revealed that the mineralogical and geochemical composition of the material is largely

9 dependent on hydrological conditions. The differentiation of element composition is

10 especially emphasized at low water stage when most of the SPM consists of slow-settling

11 mineral phases (clay minerals and metal oxyhydroxides) which can be trapped in the

12 sampler. During periods of high discharges, differentiation is less prominent, and

13 homogenization of the SPM occurs, mainly as a part of bed load is also taken into 
14 suspension. These conditions have proven unfavorable for sampler efficiency, as at least part of the finest particles could not be retained. Additional issues that may occur during TIMS employment relate to biologically driven carbonate precipitation, which is triggered by changes in physico-chemical conditions at low water table in the summer period. Increased concentration of $\mathrm{Ca}$, related to that process, influences the elemental composition of the SPM, which is particularly important when anthropogenic impact or sediment source is assessed. Hence, in order to interpret the geochemical and mineralogical data collected by TIMS, these factors should be taken into account. Our findings emphasize the need for detailed studies of chemical composition of the SPM (time-integrated) in medium-sized rivers and point out the significance of evaluating sampling representativeness during different hydrological conditions.

Keywords: Geochemical composition; Hydrodynamic sorting; Time-integrated sampler; the Sava River catchment

\section{Introduction}

The suspended particulate material (SPM) refers to particles that suspend in the water column with a lower size limit of 0.20 or $0.45 \mu \mathrm{m}$ in median diameter (Viers et al. 2009). It consists of inorganic (quartz, feldspars, carbonates, clay minerals, metal oxyhydroxides,

31 heavy minerals) and organic (microorganisms and detritus) particulate matter (Gregory, 2006; Garzanti et al., 2011) usually presented in flocculated form (Droppo and Ongley, 1994). The SPM has a major role in transfer of elements from source to sink. According to Horowitz (1991) and Audry et al. (2004), more than $90 \%$ of the riverine flux of metals is associated with fine-grained sediment. So, when dealing with the trace elements input/transfer/transport along a river, the investigation should focus on the SPM. However, most of the SPM-bound element load is related to high flow events which are extremely irregular. Another difficulty is to collect a representative sample and sufficient amount of the SPM for analyzing different chemical and/or physical characteristics. In order to meet these requirements, Phillips et al. (2000) developed a time-integrated suspended sediment sampler 
41 (TIMS), mainly designed for streams and small lowland rivers (Schindler Wildhaber et al. 2012; Smith and Owens, 2014). Heretofore, TIMS was used in different studies (Russel et al., 2000; McDonald et al., 2010; Droppo et al., 2019) and proven effective in several environmental and controlled laboratory conditions (Martínez-Carreras et al. 2012; Marttila et al. 2013; Perks et al., 2014). The amount of material collected was found sufficient and the representativeness of TIMS was also proven satisfying. The main objections were the poor assessment of the SPM mass flux (Goharrokhi et al., 2019) and lack of knowledge of how it operates in larger river systems (Smith and Owens, 2014).

TIMS was also used in our previous research (Lučić et al., 2019) to investigate the Sava River SPM and associated anthropogenic impact. The TIMS was set at one location in the Sava River in Zagreb during different discharge periods. The results have shown increased concentrations of some ecotoxic elements ( $\mathrm{As}, \mathrm{Bi}, \mathrm{Cd}, \mathrm{Cr}, \mathrm{Ni}, \mathrm{Pb}, \mathrm{Sb}, \mathrm{Zn}$ ). Some issues opened during that investigation: the input of the material from different sources during different discharge periods and high concentration of calcite in spring sampling period was observed. A possibility of in situ calcite precipitation instigated by algal bloom was hypothesized.

This investigation has been conducted in order to obtain more information on the hydrodynamic sorting and representativeness of the SPM (time-integrated) transported in a medium size river. The case study was the Sava River and main tributaries (Ljubljanica, Savinja and Krapina) between its source and the city of Zagreb, as an example of medium size river in the anthropogenically impacted environment. The aims of the study were:

1. to characterize the spatial and time variation of the geochemical composition of the SPM sampled by TIMS in different hydrological conditions,

2. to assess potential influence of hydrodynamic sorting on suspended material,

3. to determine possible differences between shallow and deeper suspended load using two TIMS samplers at one location. 


\section{Materials \& methods}

\subsection{Study area}

71 The Sava River is a major Danube tributary which flows through Slovenia and Croatia, alongside the northern border of Bosnia and Herzegovina, and finally through Serbia. The upper course of river is $232 \mathrm{~km}$ long with drainage basin covering $12680 \mathrm{~km}^{2}$ of surface area (Table 1). Other detailed geographical characteristics of the Sava River can be found in our previous work (Lučić et al., 2019).

Table 1 Main characteristics of studied rivers (average discharge refers to the outlet of the river)

\begin{tabular}{c|ccccc}
\hline Rivers & $\begin{array}{c}\text { Basin area } \\
\left(\mathrm{km}^{2}\right)\end{array}$ & Length $(\mathrm{km})$ & $\begin{array}{c}\text { Average } \\
\text { Discharge } \\
\left(\mathrm{m}^{3} \mathrm{~s}^{-1}\right)\end{array}$ & $\begin{array}{c}\text { Average slope } \\
(\mathrm{m} / \mathrm{km})\end{array}$ & $\begin{array}{c}\text { Annual sediment } \\
\text { runoff } \\
\mathrm{Gg}\left(\mathrm{m}^{2}\right)\end{array}$ \\
\hline Sava (Radovljica) & 909 & 55 & 44.9 & - & 192 \\
Sava (Rugvica) & 12680 & 232 & 310 & 200 & - \\
Ljubljanica & 1884 & 41 & 57.3 & 158.8 & 70 \\
Savinja & 1849 & 93.9 & 41.5 & 272 & 145 \\
Krapina & 1237 & 66.9 & 10.9 & 143.7 & 179 \\
\hline
\end{tabular}

78

The Sava River has its origin as two branches, the Sava Dolinka and Sava Bohinjka rivers which flow mainly through carbonate terrain (limestone and dolostone) until their confluence at the city of Radovljica. From there, the river passes through previously deposited fluvioglacial terraces which alternate with Paleozoic rocks consisting of shales, quartz sandstones and conglomerates. Besides Permo-Carbonian clastic sediments, the central part of the Sava section in Slovenia is composed of Triassic carbonates, together with Paleogene and Neogene clastic rocks in the area before the border with Croatia (Placer, 2008). In Croatia, the drainage area of the river comprises terraced Quaternary deposits consisting of sands, marls and clays (Šikić et al., 1979).

The Ljubljanica River flows through Ljubljana Moor, paleo-swamp filled with Quaternary alluvial sediments (pebble, sand and clay) covering Paleozoic basement and Mesozoic limestone and dolostone. Because of the considerable thickness of fluvio-glacial sediments, the Ljubljansko Barje is one of the most important aquifers in Slovenia (Cerar and Urbanc, 2013). 
The Savinja River, the second longest Slovenian river originates in the Kamnik-Savinja Alps in Triassic carbonates and flows through Oligocene tuffs and andesites, while in the lower part drains the Triassic carbonates and Miocene sandstones. As a result of its runoff characteristics, its catchment area contributes up to $40 \%$ of the lower Sava River (in Slovenia) discharge in high rainfall events (Kobold and Sušelj, 2005).

The Krapina River has its origin in the Paleogene and Neogene of the Panonnian Basin. On the left side of the flow, the Krapina River is filled by many streams that drain the Medvednica mountain, consisting of rocks of different ages (from Silurian to Quaternary age) (Galović and Peh, 2014).

\subsection{Sampling and preparation of samples}

TIMS samplers used in this study were slightly modified with respect to the original design. According to Perks et al. (2014), TIMS does not operate isokinetically under the flow velocities below $0.55 \mathrm{~m} \mathrm{~s}^{-1}$ which may spoil representativeness of sampled material. Therefore, we used modified larger inlet and outlet (6 $\mathrm{mm}$ diameter), while tube diameter was $110 \mathrm{~mm}$ in width. The samplers were positioned at five locations (Fig. 1, Table 2), protected by metal cages and fixed by steel uprights. At Zagreb location, sampling was conducted during a hydrological year with five campaigns organized from October 2016 to July 2017. During the spring and summer period, two samplers were positioned simultaneously: one at the bottom and another tied under the pontoon and sunk $30 \mathrm{~cm}$ below the water surface. The intention was to collect and compare shallow and deeper suspended load at the same location. The shallower channel of the Sava River at Radovljica site and tributaries did not allow sampling on the vertical profile. Sampling frequencies at these locations (Sava Radovljica, Ljubljanica, Savinja, Krapina) were less frequent; at least two sampling campaigns were performed at each site.

\section{Figure 1.}


120 Besides suspended material collected by TIMS, in the period of time-integrated sampling at

121 the Sava River, single-point samples of suspended material were also taken, as well as the

122 bottom river sediments. The frequency of sampling is shown in Table 2.

123 The sediments were sieved through a $63 \mu \mathrm{m}$ sieve using ambient water. Single-point SPM

124 samples were taken in plastic $6 \mathrm{~L}$ bottles and subsequently filtered in laboratory $(0.45 \mu \mathrm{m}$

125 cellulose acetate, Sartorius) and dried at $60^{\circ} \mathrm{C}$. TIMS samples were transferred into glass

126 beakers and left to settle; the supernatant was then carefully decanted.

127 The supernatant, remaining after single-point SPM and TIMS samples were separated,

128 filtered using in-line syringe cellulose nitrate filters $(0.45 \mu \mathrm{m}$, Sartorius), transferred into 10

$129 \mathrm{~mL}$ Teflon tubes and acidified with nitric acid (supra pure 65\%, Fluka) for determination of

130 soluble elements (European Communities Environmental Objectives 2009; Gottler 2012).

131 For all the analyses except particle size determination, a portion of each sample was freeze-

132 dried (FreeZone 2.5; Labconco) and ground to fine powder using a ball-mill (Pulverisette 7;

133 Fritsch).

134 Table 2 Sampling schedule for SPM and sediment samples in each sampling campaign.

\begin{tabular}{|c|c|c|c|c|c|c|}
\hline River & Sample & Location & Coordinates & Sampling period & $\begin{array}{c}\text { Number of } \\
\text { single- } \\
\text { point samples }\end{array}$ & $\begin{array}{c}\text { Number of } \\
\text { sediment } \\
\text { samples }\end{array}$ \\
\hline Sava & $Z G$ & $\begin{array}{l}\text { Zagreb } \\
\text { (Croatia) }\end{array}$ & $\begin{array}{l}\text { N } 45^{\circ} 47^{\prime} 08.1^{\prime \prime} \\
\text { E 1557'21.9" }\end{array}$ & $\begin{array}{c}\text { October.2016 } \\
\text { November.2016 } \\
\text { February.2017 } \\
\text { April.2017 } \\
\text { July.2017 } \\
\end{array}$ & $\begin{array}{l}4 \\
4 \\
4 \\
5 \\
5 \\
\end{array}$ & $\begin{array}{l}1 \\
1 \\
1 \\
2 \\
1 \\
\end{array}$ \\
\hline Sava & SRAD & $\begin{array}{l}\text { Radovljica } \\
\text { (Slovenia) }\end{array}$ & $\begin{array}{l}\text { N } 45^{\circ} 47^{\prime} 08.1^{\prime \prime} \\
\text { E 155'ㄱ'21.9" }\end{array}$ & $\begin{array}{c}\text { October.2016 } \\
\text { November.2016 }\end{array}$ & $\begin{array}{l}4 \\
4\end{array}$ & $\begin{array}{l}1 \\
1\end{array}$ \\
\hline Ljubljanica & LJ & $\begin{array}{l}\text { Ljubljana-Podgrad } \\
\text { (Slovenia) }\end{array}$ & $\begin{array}{l}\text { N } 46^{\circ} 04^{\prime} 23.2^{\prime \prime} \\
\text { E } 14^{\circ} 38^{\prime} 09.7^{\prime \prime}\end{array}$ & $\begin{array}{c}\text { February.2017 } \\
\text { April.2017 } \\
\text { July.2017 } \\
\text { November } 2017 \\
\end{array}$ & $\begin{array}{l}1 \\
2 \\
1 \\
1 \\
\end{array}$ & $\begin{array}{l}2 \\
2 \\
1 \\
1 \\
\end{array}$ \\
\hline Savinja & SV & $\begin{array}{l}\text { Veliko Širje } \\
\text { (Slovenia) }\end{array}$ & $\begin{array}{l}\text { N } 46^{\circ} 05^{\prime} 28.7^{\prime \prime} \\
\text { E 1511'31.4" }\end{array}$ & $\begin{array}{c}\text { February.2017 } \\
\text { April.2017 } \\
\text { July.2017 } \\
\text { November } 2017 \\
\end{array}$ & $\begin{array}{l}1 \\
2 \\
1 \\
1 \\
\end{array}$ & $\begin{array}{l}1 \\
2 \\
2 \\
2 \\
\end{array}$ \\
\hline Krapina & $\mathrm{KR}$ & $\begin{array}{l}\text { Zaprešić } \\
\text { (Croatia) }\end{array}$ & $\begin{array}{l}\text { N } 45^{\circ} 50^{\prime} 23.4^{\prime \prime} \\
\text { E 15॰49'36.3" }\end{array}$ & $\begin{array}{c}\text { April } 2017 \\
\text { July.2017 } \\
\text { November } 2017\end{array}$ & $\begin{array}{l}1 \\
2 \\
1\end{array}$ & $\begin{array}{l}2 \\
1 \\
1\end{array}$ \\
\hline
\end{tabular}

\subsection{Methods}

136 Particle size distribution (PSD) was determined using a laser-based particle size analyzer

137 (LS 13320; Beckman Coulter Inc.). The PSD was calculated using Mie theory of light 
138 scattering (optical parameters: refractive index $=1.53$; absorption index $=0.1$ ). The mineral

139 composition was identified by X-ray powder diffraction using a Philips X-Pert MPD

140 diffractometer (40 kV, $40 \mathrm{~mA}$, range scanned $\left.4-63^{\circ} 2 \theta\right)$. Bulk composition of 10 TIMS and 7

141 sediment samples was determined. For 6 chosen TIMS samples, the clay fraction $(<2 \mu \mathrm{m})$

142 was separated by centrifugation and analyzed on oriented slides after being air-dried,

143 saturated by ethylene glycol, and heated for $1 \mathrm{~h}$ at $400^{\circ}$ and $550^{\circ} \mathrm{C}$. Proportions of minerals

144 were evaluated semi-quantitatively using distinctive peak areas (Moore and Reynolds, 1997;

145 Kahle et al., 2002), weighted by Schultz (1964) empirical factors, which represents rough

146 estimate of mineral percentages.

147 Prior to geochemical analysis, sediment and TIMS samples were digested by a two-step 148 procedure (I-5 ml $\mathrm{HNO}_{3}(65 \%$, pro analysi, Kemika $)+1 \mathrm{ml} \mathrm{HCl}(37 \%$, VLSI Grade,

149 Rotipuran) $+1 \mathrm{ml} \mathrm{HF} \mathrm{(47-51 \% ,} \mathrm{supra} \mathrm{pur,} \mathrm{Fluka);} \mathrm{II-6} \mathrm{ml} \mathrm{H}_{3} \mathrm{BO}_{3}\left(40 \mathrm{~g} \mathrm{I}^{-1}\right.$, Fluka)) in the

150 Microwave digestion system Multiwave 3000 (Anton Paar). Due to small amount of sample,

151 single-point SPM samples were dissolved by modified procedure (I-4 $\mathrm{ml} \mathrm{HNO}_{3}+1 \mathrm{ml}$

$\left.152 \mathrm{HCl}+0.2 \mathrm{ml} \mathrm{HF} ; \mathrm{Il}-1.25 \mathrm{ml}^{2} \mathrm{~g} \mathrm{I}^{-1} \mathrm{H}_{3} \mathrm{BO}_{3}\right)$.

153 Multi-elemental analysis of dissolved and particulate fraction was conducted using a High-

154 Resolution Inductively Coupled Plasma Mass Spectrometer (HR ICPMS), Element 2 (Thermo

155 Finnigan). Analytical quality control was provided by simultaneous analysis of blanks and

156 certified reference materials (Soil-NCS DC 77302 and Stream Sediment-NCS DC 73309) for

157 which good recoveries (90-100 \%) were obtained, depending on the element measured.

158 Details of the method are provided in Fiket et al. (2017). For water samples measurement

159 uncertainty was better than $\pm 3 \%$.

160 The hydrological data were provided by Meteorological and Hydrological Service of Croatia

161 (DHMZ) and Slovenia (ARSO). Discharge measurements were performed by conventional

162 current meter method. The SPM concentration was measured daily by filtration of surface

163 water samples taken in the middle of the river course, $10-20 \mathrm{~cm}$ below the water level.

164 Statistical treatments were performed using a R package "robCompositions" while heat-maps

165 were designed in package "gplots" in R platform (R Core Team, 2017). 


\section{Results and discussion}

\subsection{Hydrological and particle size characteristics}

168 Five sampling campaigns conducted in Zagreb encompassed a wide spectrum of discharges and SPM trends (Fig. 2). Except for the calm summer period, all seasons were characterized by at least one increase in water discharge followed by corresponding variation of the SPM

171 content. Compared to the Sava, Ljubljanica and Savinja rivers have revealed similar trends of

172 discharge fluctuations (Fig. A.1 and A.2). Somewhat different hydrological conditions were 173 observed for the Krapina River in which high SPM concentration did not always follow the 174 rise of the water level (Fig. A.3), mainly as a result of different sediment sources (Morehead 175 et al., 2003).

176 In the Sava River SPM (both in TIMS and single-point samples), and in sediment samples, 177 predominant particle-size fraction was silt, regardless of the sampling period (Table 3). Due 178 to insufficient quantity, particle size analysis was made only for a few of the single-point SPM 179 samples. Fine-grained sediments were dominated by finer particle size ranging from 11.1 to

$18034.7 \mu \mathrm{m}$, compared to single-point $(19.6-56.3 \mu \mathrm{m})$ and TIMS samples $(40.6-56 \mu \mathrm{m})$. After

181 organic matter removal, a notable increase in clay content and consequently lower mean

182 grain size $(\mathrm{Mz})$ was observed in all samples. These changes were more pronounced in TIMS 183 samples than in fine-grained sediments, which indicates that the flocculation process took 184 place in the river channel. Also, lower $\mathrm{Mz}$ in treated sediments compared to TIMS samples 185 suggests that the part of the finest material carried in suspension could pass through the 186 sampler in a case of a high flow rate.

\section{Figure 2.}

189 For the other rivers, the sediment particle size showed comparable variations, $\mathrm{Mz}$ of the

190 Ljubljanica River ranging from 15.8 to $23.1 \mu \mathrm{m}$, similar to Savinja (15.4 - $23.2 \mu \mathrm{m}$ ) and

191 Krapina rivers $(15.1-18.4 \mu \mathrm{m})$. Regarding TIMS samples, the ones from the Krapina River

192 had lower Mz (19.5 - $44.2 \mu \mathrm{m})$, compared to those from Savinja $(24.7-71.6 \mu \mathrm{m})$ and

193 Ljubljanica rivers $(64.9-102.3 \mu \mathrm{m})$. In all treated samples there was a decrease in $\mathrm{Mz}$. The 
194 largest deviations between sediment and TIMS samples were observed for the Savinja and

195 Ljubljanica rivers. The presence of coarser particles in TIMS of the Savinja River was a result

196 of its stronger erosive power emphasized during the high water level when the part of bed

197 load could also be taken into suspension (Singh, 2009). The abundance of sand-sized

198 particles in all samples of the Ljubljanica River was largely the effect of erosion of soil

199 aggregates along the watercourse (Woodward and Walling, 2007).

200 Grain-size data obtained for the shallow (TMZG4) and deep-positioned (TMBZG4) TIMS of

201 the Sava River did not differ substantially (Table 3) which was not the case in the summer

202 sampling campaign; deep-positioned TIMS (TMBZG5) contained higher share of clay

203 fraction. However, when treated samples were compared, Mz in shallow positioned TIMSs

204 decreased substantially while no such effect was observed for deep-positioned TIMSs. This

205 could be related to the transport of aggregated soil particles in shallow relative to deeper load

206 which contained more sand consisting of quartz, carbonates, tectosilicates and heavy

207 minerals.

208

209 Table 3 Particle size distribution (\%), mean size (Mz), and median size (d50) of the non-treated SPM

210 samples collected by TIMS (TM), bottom positioned TIMS (TMB), single-point SPM (SPM) samples

211 and fine-grained sediments (SED). The results for chemically dispersed samples are also shown. The

212 abbreviations refer to sampling locations.

\begin{tabular}{|c|c|c|c|c|c|c|c|c|c|c|}
\hline & \multicolumn{5}{|c|}{ Non-treated } & \multicolumn{5}{|c|}{ Chemically dispersed } \\
\hline & Clay & Silt & Sand & Mz & d50 & Clay & Silt & Sand & Mz & d50 \\
\hline TMZG1 & 7.9 & 73.8 & 18.3 & 44.3 & 20.2 & 23.2 & 71.4 & 5.4 & 18.8 & 8.1 \\
\hline SEDZG1 & 17.6 & 81.4 & 1.0 & 11.1 & 7.5 & 27.5 & 68.8 & 3.7 & 15.3 & 5.9 \\
\hline SPMZG1-1 & 5.9 & 66.8 & 27.3 & 56.3 & 29.0 & 1 & 1 & 1 & 1 & 1 \\
\hline SPMZG1-2 & 12.8 & 82.3 & 4.9 & 19.6 & 13.0 & / & l & / & / & / \\
\hline TMZG2 & 6.0 & 72.1 & 21.9 & 56.0 & 26.5 & 22.3 & 72.9 & 4.8 & 17.7 & 9.1 \\
\hline SEDZG2 & 15.6 & 81.8 & 2.6 & 15.7 & 9.1 & 24.9 & 73.1 & 2.0 & 15.1 & 8.4 \\
\hline SPMZG2-1 & 15.7 & 58.9 & 25.4 & 42.1 & 15.3 & 1 & 1 & I & I & I \\
\hline SPMZG2-2 & 15.1 & 75.8 & 9.1 & 23.0 & 10.7 & I & I & 1 & I & 1 \\
\hline TMZG3 & 7.2 & 77.7 & 15.1 & 48.9 & 17.9 & 37.3 & 60.7 & 2.0 & 12.2 & 6.0 \\
\hline SEDZG3 & 15.9 & 80.5 & 3.6 & 16.3 & 8.2 & 27.9 & 70.2 & 1.9 & 12.9 & 6.6 \\
\hline SPMZG3 & 9.1 & 72.7 & 18.2 & 51.7 & 18.1 & I & I & I & 1 & 1 \\
\hline TMZG4 & 9.5 & 72.1 & 18.4 & 40.6 & 20.7 & 22.8 & 67.9 & 9.3 & 23.7 & 10.2 \\
\hline TMBZG4 & 9.6 & 65.5 & 25.0 & 50.9 & 22.9 & 21.1 & 61.1 & 17.8 & 40.3 & 12.9 \\
\hline SEDZG4 & 10.8 & 76.1 & 13.1 & 34.7 & 16.8 & 24.0 & 72.7 & 3.3 & 16.7 & 8.0 \\
\hline SPMZG4 & 8.8 & 75.3 & 15.9 & 36.1 & 18.2 & 1 & I & 1 & I & 1 \\
\hline TMZG5 & 8.7 & 66.5 & 24.8 & 52.2 & 23.8 & 46.3 & 45.2 & 8.5 & 21.3 & 3.1 \\
\hline TMBZG5 & 15.2 & 78.7 & 6.1 & 21.6 & 9.6 & 30.7 & 62.9 & 6.4 & 18.8 & 7.5 \\
\hline SEDZG5 & 13.8 & 84.1 & 2.1 & 15.0 & 9.4 & 30.3 & 64.9 & 4.8 & 16.9 & 6.3 \\
\hline TMRAD1 & 9.0 & 63.7 & 27.3 & 72.6 & 25.5 & I & 1 & I & I & I \\
\hline SRAD1 & 9.6 & 63.5 & 26.9 & 43.5 & 40.1 & I & I & 1 & I & I \\
\hline TMRAD2 & 9.6 & 71.2 & 19.2 & 54.1 & 26.5 & 1 & I & I & I & I \\
\hline
\end{tabular}




\begin{tabular}{|c|c|c|c|c|c|c|c|c|c|c|}
\hline SRAD2 & 9.5 & 74.6 & 15.9 & 37.0 & 32.9 & I & 1 & I & 1 & I \\
\hline TMLJ1 & 6.5 & 71.2 & 22.3 & 64.9 & 19.8 & 35.7 & 56.5 & 7.8 & 23.1 & 7.3 \\
\hline SEDLJ1-1 & 15.0 & 82.3 & 2.7 & 15.8 & 9.1 & 1 & 1 & 1 & 1 & I \\
\hline SEDLJ1-2 & 13.5 & 81.5 & 5.0 & 18.8 & 10.3 & 32.7 & 61.7 & 5.6 & 19.9 & 7.5 \\
\hline TMLJ2 & 6.9 & 65.9 & 27.2 & 65.1 & 27.4 & 35.2 & 51.6 & 13.2 & 36.8 & 8.5 \\
\hline SEDLJ2-1 & 8.5 & 88.0 & 3.5 & 21.7 & 15.7 & 30.5 & 66.3 & 3.2 & 16.4 & 8.2 \\
\hline SEDLJ2-2 & 12.4 & 84.4 & 3.2 & 18.2 & 11.3 & 29.8 & 66.1 & 4.1 & 15.8 & 8.1 \\
\hline TMLJ3 & 5.6 & 54.7 & 39.7 & 102.3 & 40.0 & 65.2 & 27.1 & 7.7 & 17.2 & 0.2 \\
\hline SEDLJ3 & 10.4 & 86.5 & 3.1 & 19.2 & 12.7 & 35.9 & 60.5 & 3.6 & 13.9 & 5.7 \\
\hline TMLJ4 & 4.9 & 57.6 & 37.5 & 90.9 & 38.5 & 30.9 & 46.4 & 22.7 & 83.8 & 11.6 \\
\hline SEDLJ4-1 & 10.2 & 85.6 & 4.2 & 21.5 & 12.3 & 30.4 & 63.8 & 5.8 & 19.8 & 9.4 \\
\hline SEDLJ4-2 & 10.4 & 83.8 & 5.8 & 23.1 & 12.7 & 31.9 & 64.3 & 3.8 & 15.1 & 7.8 \\
\hline TMSV1 & 10.2 & 81.3 & 8.5 & 25.8 & 11.5 & 22.9 & 66.7 & 10.4 & 27.4 & 9.4 \\
\hline SEDSV1 & 10.8 & 82.3 & 6.9 & 23.2 & 14.4 & 26.3 & 69.6 & 4.1 & 18.1 & 7.8 \\
\hline TMSV2 & 17.4 & 73.9 & 8.7 & 24.7 & 10.2 & 20.1 & 66.8 & 13.1 & 30.5 & 11.5 \\
\hline SEDSV2-1 & 12.5 & 85.0 & 2.5 & 17.0 & 10.4 & 27.1 & 68.8 & 4.1 & 16.9 & 7.7 \\
\hline SEDSV2-2 & 13.7 & 83.4 & 2.9 & 16.4 & 9.6 & I & I & I & I & I \\
\hline TMSV3 & 10.6 & 77.5 & 11.9 & 29.7 & 16.7 & 33.3 & 62.9 & 3.8 & 14.1 & 6.4 \\
\hline SEDSV3 & 11.3 & 85.0 & 3.7 & 18.7 & 11.2 & 30.7 & 67.6 & 1.7 & 11.8 & 6.1 \\
\hline TMSV4 & 6.5 & 64.0 & 29.5 & 71.6 & 30.0 & 26.9 & 62.4 & 10.7 & 24.4 & 9.5 \\
\hline SEDSV4-1 & 12.8 & 85.5 & 1.7 & 15.4 & 10.2 & 29.9 & 68.6 & 1.5 & 12.5 & 6.9 \\
\hline SEDSV4-2 & 11.7 & 86.8 & 1.5 & 16.4 & 11.7 & 38.9 & 60.2 & 0.9 & 11.1 & 5.1 \\
\hline TMKR1 & 11.6 & 83.0 & 5.4 & 19.5 & 11.2 & 21.4 & 71.1 & 7.5 & 23.6 & 10.1 \\
\hline SEDKR1-1 & 10.6 & 87.5 & 1.9 & 15.8 & 10.6 & 1 & 1 & 1 & I & I \\
\hline SEDKR1-2 & 10.1 & 86.7 & 3.2 & 17.4 & 11.1 & 23.5 & 73.7 & 2.8 & 14.8 & 7.8 \\
\hline SPMKR1 & 21.9 & 61.4 & 16.7 & 28.2 & 12.9 & 1 & 1 & 1 & 1 & 1 \\
\hline TMKR2 & 8.0 & 79.5 & 12.6 & 31.1 & 17.9 & 31.6 & 57.9 & 10.5 & 26.9 & 8.5 \\
\hline SEDKR2 & 10.7 & 85.8 & 3.5 & 18.4 & 11.9 & 19.3 & 75.7 & 5.0 & 20.2 & 9.8 \\
\hline TMKR3 & 7.4 & 74.4 & 18.2 & 44.2 & 20.2 & 20.8 & 72.1 & 7.1 & 20.7 & 10.9 \\
\hline SEDKR3 & 12.2 & 85.8 & 2.0 & 15.1 & 9.6 & 22.4 & 72.8 & 4.8 & 17.9 & 9.2 \\
\hline SPMKR3 & 10.6 & 76.4 & 13.0 & 31.5 & 14.5 & 1 & 1 & 1 & I & I \\
\hline
\end{tabular}

\section{3.2. Mineralogical characteristics}

215 The mineralogical composition of material carried by rivers usually reflects watershed

216 lithology. However, determination of provenance is not straightforward and compositional

217 variability of suspended sediment should be determined (Garzanti et al., 2010). The minerals

218 present in all analyzed samples were quartz, calcite, dolomite, phyllosilicates and feldspars

219 (Table 4).

220 The most abundant minerals in sediment samples of the Sava River were quartz, calcite and

221 dolomite. The dominance of each of them alternated, depending on the sampling period. In

222 general, the highest amount of quartz was found in deeper positioned samplers and two

223 shallow samplers from the late autumn and spring sampling campaigns, when the highest

224 flow rate and SPM concentration was recorded. Regarding shallow positioned TIMS, higher

225 quartz content probably resulted from stronger erosive power during high discharge. In

226 higher energy conditions it is assumed that material is not sufficiently differentiated, mainly 
227 because of minimal chemical weathering and the dominance of physical erosion in the

228 source area.

229 The origin of carbonates in the Sava River SPM and sediments is mostly detrital. Variation of

230 dolomite content in TIMS samples can be related to both source supply and hydrodynamic

231 sorting. Even though proportions of minerals represent a rough estimate of mineral

232 percentages, higher dolomite content observed in sediments cannot be neglected. This may

233 be attributed to higher density of dolomite which affects its accumulation in finer sand and

234 coarser silt classes; more than quartz, feldspars and calcite (Garzanti et al., 2009; Garzanti

235 and Ando, 2019). The origin of calcite could be double-natured. As assumed for the other

236 minerals, in most of the sampling periods calcite was undoubtedly detrital in origin.

237 Nevertheless, the high content of calcite found in sediment (55\%) and shallow positioned

238 TIMS (69\%) might be related to biologically mediated precipitation process (Olivier et al.,

239 2011; Lučić et al., 2019) instigated in the summer period, which will be discussed in more

240 later. The higher content of phyllosilicates in TIMS compared to sediments was observed in

241 periods of lower water levels which suggests that phyllosilicates have preferential transport in

242 surface load and have a good possibility to be retained in the sampler. Their low content

243 recorded in the SPM and sediment samples of the first and final sampling campaign was a

244 consequence of dilution effect, mainly controlled by calcite and quartz abundance. Feldspar

245 minerals did not show any variation visible from mineralogical analyses.

246 Table 4 Mineral composition of analyzed samples. The amount of minerals content is obtained semi-

247 quantitatively using distinctive peak areas (Moore and Reynolds, 1997; Kahle et al., 2002).

\begin{tabular}{lccccc}
\hline & Quartz & Feldspars & Phyllosilicates & Calcite & Dolomite \\
\hline TMZG1 & 30 & 5 & 11 & 38 & 17 \\
SEDZG1 & 31 & 3 & 6 & 38 & 22 \\
TMZG2 & 39 & 7 & 11 & 20 & 23 \\
SEDZG2 & 21 & 8 & 14 & 24 & 33 \\
TMZG3 & 31 & 5 & 18 & 38 & 8 \\
SEDZG3 & 41 & 2 & 12 & 29 & 16 \\
TMZG4 & 43 & 7 & 15 & 18 & 18 \\
TMBZG4 & 46 & 6 & 15 & 14 & 19 \\
SEDZG4 & 32 & 4 & 15 & 30 & 19 \\
TMZG5 & 15 & 4 & 7 & 69 & 4 \\
TMBZG5 & 49 & 5 & 5 & 28 & 13
\end{tabular}




\begin{tabular}{lccccc} 
SEDZG5 & 16 & 6 & 14 & 55 & 9 \\
\hline TMLJ2 & 52 & 4 & 22 & 15 & 7 \\
SEDLJ2 & 36 & 7 & 22 & 15 & 20 \\
TMS2 & 53 & 3 & 17 & 11 & 16 \\
SEDSV2 & 41 & 6 & 19 & 18 & 16 \\
TMKR1 & 57 & 11 & 28 & 1 & 3 \\
SEDKR1 & 48 & 10 & 30 & 8 & 4 \\
\hline
\end{tabular}

248 Clay mineral composition obtained for TIMS samples of the Sava River was characterized by 249 prevalence of illite/mica minerals, followed by chlorite, smectite, kaolinite and vermiculite, 250 presented only in the summer sampling period (Table A.1). The comparison of clay minerals 251 in shallow and deeper positioned TIMS, showed a higher amount of illite/mica and the 252 absence of kaolinite in the latter, which implies that kaolinite does not prefer deeper transport 253 (Gippel, 1995).

254 The slightly lower carbonate content was detected in all tributary samples, as the 255 consequence of more siliciclastic lithologies. All minerals showed opposite behavior relative 256 to quartz. Additionally, TIMS samples had an increased quartz content compared to 257 sediments. These results were corroborated with grain size analysis which reflected 258 coarsening of the TIMS samples during high water stages.

\subsection{Soluble element concentrations}

261 Concentrations of 16 chemical elements, Li, Rb, Sr, V, Cr, Mo, Mn, Fe, Co, Ni, Cu, Zn, Cd, $262 \mathrm{Al}, \mathrm{Pb}$ and $\mathrm{As}$, were determined in water samples (Appendix B1). In general, there was no 263 difference in $\mathrm{Li}, \mathrm{Rb}, \mathrm{Sr}, \mathrm{Cr}, \mathrm{Mo}, \mathrm{Ni}, \mathrm{Cu}, \mathrm{Zn}, \mathrm{Cd}, \mathrm{Pb}$ and $\mathrm{As}$ concentrations between TIMS and 264 river water. Among these elements, only Mo indicated strong anthropogenic influence, 265 particularly in the Savinja River. Molybdenum concentrations were higher than $5 \mathrm{ug} \mathrm{L}^{-1}$; 266 values much higher than reported elsewhere (Smedley et al., 2017; Vidmar et al., 2017). As 267 opposed to the above mentioned elements, concentrations of $\mathrm{V}, \mathrm{Mn}, \mathrm{Fe}, \mathrm{Co}$ and $\mathrm{Al}$ 268 significantly varied, with higher concentrations inside TIMS, except for the Krapina River. On 269 average, particularly high concentrations were observed in the Savinja $\left(\sim 1500 \mathrm{ug} \mathrm{L}^{-1}\right)$ and 270 Krapina $\left(\sim 550 \mathrm{ug} \mathrm{L}^{-1}\right)$ rivers, values were much greater than the world average $\left(34 \mathrm{ug} \mathrm{L}^{-1}\right)$ 
271 (Gaillardet et al., 2003). These deviations can be related to changes in the redox conditions 272 at the sediment-water interface, mostly for redox-sensitive elements as $\mathrm{V}, \mathrm{Mn}, \mathrm{Fe}$ and Co 273 (Balistrieri et al., 1994, Tribovillard et al., 2006). The change of redox conditions inside the 274 sampler is probably the consequence of the degradation of organic matter which 275 continuously accumulates throughout the sampling period. The reaction of oxygen with 276 organic matter will occur until one of these two components is completely consumed resulting 277 in an increasing concentration of dissolved redox-sensitive elements or contribution of 278 colloidal fraction that can be found in $<0.45 \mu \mathrm{m}$ filtered water (Hill and Aplin, 2001; Morford, 279 2019).

\subsection{Geochemical composition of suspended material}

282 The geochemical composition (50 elements - major, trace and rare earth elements (REE)) of 283 the analyzed suspended sediments is given in the Appendix B2. The comparison of TIMS 284 samples showed a higher average Ca (107342 $\left.\mathrm{mg} \mathrm{kg}^{-1}\right)$ and $\mathrm{Mg}\left(22761 \mathrm{mg} \mathrm{kg}^{-1}\right)$ concentrations in the Sava River than in TIMSs positioned at other locations ( $\mathrm{Ca}-68310 \mathrm{mg}$ $\mathrm{kg}^{-1}$ and $\mathrm{Mg}-17716 \mathrm{mg} \mathrm{kg}^{-1}$ ); the highest concentrations were observed during the summer sampling period, which corroborated mineralogical records. Magnesium concentrations proved to be sensitive to hydrodynamic sorting with the highest values in TIMSs during the greatest discharge in the Sava $\left(26482 \mathrm{mg} \mathrm{kg}^{-1}\right)$ and Savinja $\left(27506 \mathrm{mg} \mathrm{kg}^{-1}\right)$ rivers. Other

290 major elements (Al, Fe, Ti, Na, K), being the part of aluminosilicates, showed the behavior 291 opposite of $\mathrm{Ca}$ and $\mathrm{Mg}$, with the highest concentrations in samples of the Krapina River. The 292 REE and most of trace elements displayed the highest concentrations in samples with more $293 \quad$ Al and Fe content.

\subsection{Correlation analysis}

296 Besides absolute element concentrations, geochemical data were also considered in terms 297 of their composite nature (Reimann et al., 2012). The principle of compositional data deems 298 each element as a part of a whole which holds only relative information and sums up to a 
constant (Pawlowsky-Glahn et al., 2015). These closed data are mutually dependent, and

300 their relevant information rather lies in the ratios between parts of a whole. In order to follow

301 that definition, we used log-ratio transformation, called symmetric coordinates (balances),

302 where elements are arranged according to a clustering procedure (Kynčlová et al. 2017;

303 Reimann et al. 2017). The correlation analysis (Fig. 3) was conducted separately for all

304 analyzed types of samples; A) TIMS, B) single-point SPM and C) fine-grained sediments. In

305 these graphs, a similarity between TIMS and single-point SPM was observed. Fig. 3A (TIMS)

306 is characterized by two large clusters. Starting from the upper-right corner, elements indicate

307 their geogenic nature. Strong clustering is determined for Ga, Sc, V, Ni, Ge, Ti, Li, Al, Rb, K,

308 LREE, Th, HREE, Nb, Y, and to a lesser extent for TI, U, Cs and Mg, which are mostly

309 detrital in origin. Here, Mg shows good correlation with both calcium and elements related to

310 aluminosilicate fraction which reflects its presence not solely in dolomite, but also its

311 incorporation into clay minerals (smectite) abundant in the studied rivers (Barth-Wirsching et 312 al., 1994). The second smaller subcluster consists of $\mathrm{Fe}, \mathrm{Na}$, and $\mathrm{Cr}$, the presence of which

313 is assumed in multiple mineral phases (phyllosilicates, feldspars and heavy minerals). Sr and

314 Ca indicate their incorporation into the carbonate minerals, mostly calcite. The second large

315 cluster of elements (Co, Ba, Pb, As, Mn, Bi, Be, Cd, Mo, Sn, Sb, Zn, Cu and W) probably

316 emphasizes their anthropogenic nature and association with the finest particles (Chen et al.,

317 2014).

318 In a single-point SPM (Fig. 3B) elements such as LREE, Th, Ga, Li, HREE, Al, V, Y, Nb, Ti,

$319 \mathrm{Sc}, \mathrm{Cs}, \mathrm{Tl}, \mathrm{Ge}, \mathrm{Rb}, \mathrm{Co}, \mathrm{Be}, \mathrm{Ba}, \mathrm{Na}, \mathrm{W}, \mathrm{Cr}$ and Fe show moderate to strong mutual positive

320 correlation, which suggests their association with clay minerals, oxyhydroxides and organic

321 matter. Because most of the single-point samples were taken during low water level and

322 strictly in a shallow part of the flow, this group represents geogenic element association

323 dominating in a wash load where quartz, tectosilicates, heavy minerals and other fast-settling

324 phases are sparse. The last cluster consists of two smaller ones. The first one is carbonate

325 and feldspar related, and consists of $\mathrm{U}, \mathrm{Mg}, \mathrm{Ca}, \mathrm{Sr}, \mathrm{K}$ and $\mathrm{Pb}$ (Garçon et al., 2014); the

326 second one is dominated by mainly anthropogenic group of elements which tend to 
concentrate in the finest part of shallow suspended load, such as $\mathrm{Ni}, \mathrm{Sn}, \mathrm{Bi}, \mathrm{Cd}, \mathrm{Sb}, \mathrm{As}, \mathrm{Mn}$,

$328 \mathrm{Cu}, \mathrm{Zn}$ and Mo.

329 The fine-grained sediments (Fig. 3C) display somewhat different clustering and not so 330 pronounced correlations. The upper-right corner suggests agglomeration of elements solely 331 detrital in origin. Moreover, the strong positive correlations of $\mathrm{Ti}, \mathrm{W}, \mathrm{Nb}, \mathrm{Ge}$ and $\mathrm{Na}$ probably 332 suggest their presence in heavy minerals and tectosilicates which tend to concentrate in 333 deeper suspended load (Garzanti et al., 2011). The second smaller subcluster consists of 334 Ga, LREE, Li and Al mainly associated with clay minerals. An association of elements such 335 as $\mathrm{V}, \mathrm{Fe}, \mathrm{Cr}, \mathrm{Sc}, \mathrm{As}, \mathrm{Pb}, \mathrm{Co}, \mathrm{Sb}, \mathrm{Y}$ and HREE may imply mafic component, especially within 336 sediments of the Savinja and Krapina rivers (Salminen et al., 2005). The heat-map of fine337 grained sediments does not reveal a prominent anthropogenic association of elements.

338 Rather, they are positioned within the group of elements mostly related to phyllosilicates and 339 feldspars (Rb, Be, Tl, Cu, Bi, Th, K, Ba, Zn, Mn and Cs). The second large cluster consists of 340 two subclusters and point out carbonate components more dominant in the Sava River.

341 Association of elements Cd-Sn is partly influenced by anthropogenic impact. Except for Sn, 342 all grouped elements ( $\mathrm{Ni}, \mathrm{Sr}, \mathrm{U}, \mathrm{Mg}, \mathrm{Cd}$, $\mathrm{Mo}$ and $\mathrm{Ca}$ ) have a similar ionic radius and can be 343 incorporated into carbonates (Rambeau et al., 2010; Lerouge et al., 2017)

\section{Figure 3.}

\subsection{Geochemical normalization}

347 To assess the representativeness of time-integrated sampler for sampling in the Sava River 348 and tributaries, we compared the geochemical composition of the SPM collected by shallow349 positioned TIMS to other sampled material (fine-grained sediment $(<63 \mu \mathrm{m})$, deep350 positioned TIMS and single-point SPM samples). In this way, important information about 351 geochemical similarity/dissimilarity between material captured in TIMS and other materials 352 present in a water column during different hydrological cycles could be attained. Single-point 353 SPM represents the current sample and we assumed the similarity to the material collected 354 by TIMS. During low discharges, the most of fine-grained sediment is settled to the bottom, 
and clay/organic particles prevail in suspension. Somewhat different behavior can be observed during the turbulent water conditions when most of the fine-grained sediment, along with the part of fine sand, becomes the main component of the suspended load. Taking into account these components, we have covered all the material on the vertical profile and can reasonably conclude on the representativeness of the material collected by TIMS. The cross-section sampling was not performed; it is assumed that fine-grained material is rather homogeneously distributed across the horizontal profile (Walling et al. 2000; Perks et al., 2014). The geochemical normalization of materials was performed using enrichment factor; all elements in a single-point SPM (average concentrations of all samples except during high water level) and fine-grained sediment were doubly-normalized to TIMS sample using a formula:

$\mathrm{EF}(\mathrm{E})=(\mathrm{E} / \mathrm{Al})_{\mathrm{SPM} / \text { sediment }} /(\mathrm{E} / \mathrm{Al})_{\mathrm{TIMS}}$ where $E$ is the element of interest normalized to insoluble element $(\mathrm{Al})$ to minimize dilution caused by quartz, carbonates or organic matter. Here, Al is chosen as a best reference nonmobile element, which is not affected by hydrodynamic sorting (Garzanti et al., 2013). EF > 1 indicates enrichment of element compared to TIMS, while EF $<1$ indicates a depletion.

\subsubsection{The Sava River}

The chemical composition of suspended sediment is usually subjected to changes throughout the hydrological cycles (Viers et al., 2008). The temporal variability of flow can cause sorting processes that are responsible for the geochemical differentiation of suspended material based on hydrodynamic properties. During the first autumn sampling campaign (Fig. 4A) the normalized elemental composition of sediment shows enrichment pattern for $\mathrm{Co}, \mathrm{Sn}$ and $\mathrm{Pb}$. Even though all analyzed materials are under the anthropogenic impact (Milačič et al., 2017), these anomalies suggest that the sediment is more influenced by anthropogenic contamination than the SPM collected by TIMS. In addition, slight enrichment of $\mathrm{Cs}$, Be, LREE, Th, U, Mo, Fe, Ni, Cu, Zn, Ga and $\mathrm{TI}$ in sediment compared to TIMS is related to elements mainly hosted in micas or associated with clay, Fe-Mn 
oxyhydroxides and organic matter, which indicates a minor loss of the suspended particles

384 from the sampler. Contrary to sediment, an average of elements in all single-point SPM samples (average of 5 samples) shows lower concentrations of $\mathrm{Na}, \mathrm{Rb}, \mathrm{Mg}, \mathrm{Ca}, \mathrm{Sr}, \mathrm{Ba}, \mathrm{Sc}$, $\mathrm{Y}, \mathrm{Eu}, \mathrm{Lu}, \mathrm{Ti}, \mathrm{V}, \mathrm{Nb}, \mathrm{Cr}, \mathrm{W}, \mathrm{Co}, \mathrm{Ni}, \mathrm{Ge}, \mathrm{Sn}$, and higher concentrations of K, Be, Th, Mn, Zn and $\mathrm{Pb}$ in relation to TIMS. The depletion of the first group of elements is caused by their tendency to accumulate in deep suspended load (Garzanti et al., 2011; Bouchez et al., 2011; Wu et al., 2013) and due to their hydrodynamic properties could be captured in the sampler at high water level when the part of bed load is also taken in suspension. It is assumed that

$391 \mathrm{Ca}, \mathrm{Mg}$ and $\mathrm{Sr}$ are mainly hosted in carbonates, $\mathrm{Na}, \mathrm{Sr}$ and Eu in tectosilicates, while Lu, Ti, $\mathrm{Nb}, \mathrm{Cr}, \mathrm{Ni}, \mathrm{Ge}$ and $\mathrm{Sn}$ can be hosted partly in ultradense minerals. Higher enrichment of $\mathrm{Mn}$ in single-point SPM is a result of its presence in clay minerals and oxyhydroxides, which

394 dominate in a shallow suspended load and are likely to escape from sampler. Nevertheless, 395 the normalized pattern of average SPM assumes reasonably good representativeness of 396 material collected by TIMS.

\section{$397 \quad$ Figure 4.}

399 The second autumn sampling campaign (Fig. 4B) is characterized by more extreme hydrological conditions (Fig. 2). In that period, single-point SPM was sampled mostly at

401 medium discharges. When compared to TIMS, sediment displays a similar pattern as 402 observed in the previous period, i.e. minor enrichment of mostly geogenic ( $\mathrm{Na}, \mathrm{Mg}, \mathrm{REE}$ and $403 \mathrm{Th}$ ) and some of anthropogenic elements (Ni, $\mathrm{Zn}, \mathrm{Cd}, \mathrm{Sn}, \mathrm{Pb}$ and $\mathrm{As}$ ). With respect to most 404 of the naturally-derived elements (from $\mathrm{Li}$ to $\mathrm{Nb}, \mathrm{W}, \mathrm{Fe}, \mathrm{Ga}$ and $\mathrm{Ge}$ ), average SPM values show good similarity to TIMS. Moreover, the SPM at high water level does not show significant enrichment which suggests that most of the material is captured inside the

407 sampler. Depletions of $\mathrm{Mg}, \mathrm{Ca}, \mathrm{Sr}$ could be explained by more siliciclastic supply in 408 conditions of high discharges, when the Sava River brings more material from the upper 409 reaches. Opposite variations of $\mathrm{Mo}, \mathrm{Mn}, \mathrm{Cu}, \mathrm{Zn}$ and $\mathrm{Cd}$ during high and low water levels are 410 probably a consequence of their different source nature. During high discharges, the SPM is 
411 mainly detrital in origin and metal-poor (Ollivier et al. 2011). Contrary, low water conditions

412 are characterized by metal-rich fraction which tends to adsorb onto clays, oxyhydroxides and

413 organic matter (Horowitz and Elrick, 1987; Baran et al., 2019). Based on that, we can

414 assume that TIMS sample represents averaged out SPM composition fairly well.

415 In the winter sampling period (Fig. 4C), single-point SPM samples were collected during low

416 discharges (Fig. 2). In these conditions, for most of the period, the lowest SPM concentration

417 was observed. Here, geochemical differences between different water stages are more

418 pronounced. High enrichment patterns for $\mathrm{Mo}, \mathrm{Mn}, \mathrm{Ni}, \mathrm{Cu}, \mathrm{Zn}, \mathrm{Cd}, \mathrm{Sn}, \mathrm{As}, \mathrm{Sb}$ and $\mathrm{Bi}$ at low

419 water stage may emphasize prominent instant anthropogenic input and preferable adsorption

420 onto clays/oxyhydroxides. During high discharges, siliciclastic and detrital influence is more

421 visible from the depletion of $\mathrm{Mg}, \mathrm{Ca}$ and $\mathrm{Sr}$ in comparison to the previous sampling period.

422 Grain-size and mineralogical data suggest a good representativeness of material captured in

423 the sampler. This is because both analyses showed a higher amount of clay fraction and

424 phyllosilicates (Table 3 and 4) compared to sediment. Also, this is supported by no

425 enrichment patterns in average SPM for most of the geogenic elements ( $\mathrm{Li} . \mathrm{Na}, \mathrm{K}, \mathrm{Rb}, \mathrm{Cs}$,

$426 \mathrm{Be}, \mathrm{Ba}, \mathrm{Sc}, \mathrm{REE}, \mathrm{Th}, \mathrm{Ti}, \mathrm{V}, \mathrm{Nb}, \mathrm{Fe}, \mathrm{Ga}$ and $\mathrm{Ge}$ ). However, geochemical normalization of high

427 water SPM and sediment samples showed slight enrichments of REE and Th in relation to

428 TIMS. According to Garzanti et al., (2011) these elements can be enriched in both, shallow

429 and deeper suspended load, mainly as a result of provenance effect, concentration in

430 ultradense minerals, phyllosilicates and organic matter. Herein, we assumed that enrichment

431 in SPM/sediment sample could reflect instant provenance signal and scavenging of Th and

432 particularly MREE (Sm, Eu, Gd and Tb) onto Mn/Fe-oxyhydroxides and clays (Quinn et al.,

433 2006).

434 The spring sampling campaign (Fig. 4D) is characterized by calm hydrological conditions,

435 disturbed during the last three days of sampling (Fig. 2). In this period, the highest discharge

436 and SPM concentration were observed. The results obtained for sample from deep-

437 positioned TIMS corroborated previously stated inferences about hydraulic behavior of

438 elements; enrichment/accumulation of $\mathrm{Na}, \mathrm{Mg}, \mathrm{Ca}, \mathrm{Sr}, \mathrm{Ba}, \mathrm{Ti}, \mathrm{Nb}, \mathrm{Cr}, \mathrm{Ge}$ and $\mathrm{Sn}$ in the bed 
load. Other enriched values of REE, V, Fe, Co, Ni and Cu suggest that these elements are not solely dominant in a shallow load, but also partly transported in a deeper load hosted in

441 heavy minerals (Garzanti et al., 2011). Based on slight enrichment of mostly geogenic

442 elements (K, Rb, REE, U) in sediment and SPM at high water stage, together with lower 443 mean particle-size observed in sediment sample, a minor loss of finest particles from TIMS is 444 presumed. Similarly to previous sampling period, consecutive enrichments of $\mathrm{Mo}, \mathrm{Mn}, \mathrm{Ni}, \mathrm{Cu}$, $445 \mathrm{Zn}, \mathrm{Cd}, \mathrm{Sn}$ and $\mathrm{Pb}$ are observed. This may suggest that comparing potentially anthropogenic 446 elements in different materials should be taken with care since this group of elements 447 represents fraction more sensitive to physico-chemical changes $(\mathrm{pH}$, redox condition, 448 temperature, electric conductivity, a form of elements, etc.) in water. Therefore, in evaluating 449 time-integrated sampling in human-impacted rivers, focus should be put on naturally-derived 450 elements that are more stable and associated with the residual fraction (Aguilar-Hinojosa et 451 al., 2016; Baran et al., 2019).

452 As discussed earlier, the summer sampling period (Fig. 4E) was characterized by low 453 discharges and unusually high concentration of $\mathrm{Ca}$ in shallow positioned sampler.

454 Considering that $\mathrm{Ca}$ tends to accumulate in coarser sediment fraction, that may imply the 455 origin of Ca different than only detrital (Chen et al., 2014). An explanation could be intense 456 biological production at low water stage during which the elements are accumulated by the 457 long-chain organic acids (Rogerson et al., 2008). In addition, the slow-moving water 458 conditions in the sampler promoted biogenic calcite precipitation (Olivier et al., 2011), which 459 resulted in unusually high concentration of calcium. These processes invoked the 460 disturbance of the chemical composition of collected material which made the conclusion 461 about sampler's representativeness more difficult to reach. This is most apparent in higher 462 enrichments of all elements (except $\mathrm{Ca}$ and $\mathrm{Mn}$ ) observed in the sediment which would mean 463 a notable loss of particles from the sampler that is in contradiction with other obtained results. 464 Namely, higher clay content and lower grain size determined in a shallow compared to 465 deeper TiMS and sediment samples suggest good effectiveness of TIMS that is most 
466 probable to occur in these low water conditions. Therefore, an estimation of the chemical

467 composition in the summer sampling campaign should be interpreted with caution.

468 For the sampling location Radovljica (the Sava River headwaters), a smaller range of

469 elements was analyzed (Fig. 5.). The results of single-point SPM have emphasized enriched

470 patterns of mostly anthropogenic $(\mathrm{Ni}, \mathrm{Cu}, \mathrm{Zn}, \mathrm{Cd}$ and $\mathrm{Pb})$ and naturally derived $(\mathrm{Rb}, \mathrm{V}$ and

471 Mn) elements. As aforementioned, these disparities are related to organic- and metal-rich

472 fraction abundant at low water levels. By observing grain-size distribution of the sediment

473 samples, TIMS could be evaluated as quite effective. Higher Cr values may reflect

474 anthropogenic impact (Milačić et al., 2017) or appearance of mafic minerals that concentrate

475 at the riverbed (Hinterlechner-Ravnik and Pleničar, 1967; Garzanti et al., 2011).

$476 \quad$ Figure 5.

\subsubsection{Tributaries}

479 The results of normalized diagrams of the Ljubljanica, Savinja and Krapina rivers have shown 480 somewhat different EFs compared to the Sava River (Fig. 6A, B and C). These tributaries 481 have a dissimilar morphology and shallower channels, which promotes coarser particles to 482 be collected by TIMS. Besides, the positioning of TIMS close to riverbed facilitates the 483 accumulation of coarse material regardless the variation of the hydrological cycle; the 484 increase of water level up to $2 \mathrm{~m}$ is not uncommon. This can also explain high quartz content 485 determined in TIMS samples. Discrepancies found between single-point SPM and sediments 486 reflect the influence of hydrodynamic sorting on geochemical and mineralogical composition.

487 Because single-point SPM was collected only during low water stage, most of the particles 488 that contain geogenic elements are likely to be captured by TIMS.

489 TIMSs positioned in the Ljubljanica and Savinja rivers (Fig. 6A and B) were characterized 490 with higher concentration of Be and W, particularly in the summer period. The most probable 491 explanation would be their interaction with organic matter (Tuna et al., 2012; Boschi and 492 Willenbring, 2016) or the adsorption on the secondary Fe-Mn oxyhydroxides (Armiento et al., 
2013; Bauer et al., 2017), rather than the selective entrainment of heavy minerals (Garzanti et al., 2010). As mentioned earlier, long-time sampling inside TIMS can probably cause a change of physico-chemical conditions at the sediment-water interface. The reductive dissolution of oxyhydroxide particles below this layer releases soluble $\mathrm{Mn}$ and induces its upward moving into the water column but subsequently trapping it back as Mn oxides when oxygenated water is encountered (Calvert and Pedersen, 1996; Tribovillard et al., 2006). Inside the TIMS, this precipitation resulted in strong binding of $\mathrm{Be}$ and $\mathrm{W}$ with $\mathrm{Mn}$, and consequently their prominent depletions. This process could also be responsible for depletion patterns of $\mathrm{Mn}, \mathrm{Pb}, \mathrm{Zn}$, As and $\mathrm{Sb}$ observed in sediment samples in comparison to TIMS of the Krapina River (Fig. 6C). As in the case of the Sava River, these variations can reflect their sensitivity to physico-chemical changes at the boundary between sediment and the overlying water (Baran et al., 2019). The higher EFs found in sediments for the most of detrital elements (Cs, Ba, Sc, REE, Th, $U, G a$ ) indicate that their main carriers are not easiliy retained at high flow rate. This pertains particularly to the Savinja (Fig. 6B), as the hydrologically most demanding river, in which higher loss of particles is expected. Since Ljubljanica and Krapina are typical lowland rivers with lower discharge and lower enrichment patterns, more efficient retention of particles in TIMS is likely to occur.

\section{Figure 6.}

\section{Conclusions}

In this study, we have combined hydrological observations, granulometric, mineralogical and geochemical data of the SPM in a medium-size river to characterize element behavior and representativeness of material collected by time-integrated mass-flux sampler (TIMS). To evaluate TIMS in real-environment conditions, we have compared different sampled materials (SPM collected by TIMS, single-point SPM samples and fine-grained sediment $(<$ $63 \mu \mathrm{m}))$. The main findings are as follows:

1. The flocculation process in the river channel induces coarser particle size in the singlepoint SPM and the SPM collected by TIMS compared to fine-grained sediments $(<63 \mu \mathrm{m})$, 
521 which otherwise represent their suitable representative. After organic matter removal, a

522 notable increase in clay content and lower mean grain size were observed.

523 2. The mineral composition of all samples is dominated by quartz, carbonates, phyllosilicates

524 and feldspars which are mainly detrital in origin. However, a high content of calcite in

525 sediment (55\%) and shallow TIMS (69\%) determined in the summer period can be the result

526 of biologically instigated carbonate precipitation, supported by lower water table and almost

527 stagnant water conditions.

528 3. The geochemistry of analyzed materials is mostly influenced by the hydrodynamic sorting

529 and provenance; different compositions during different hydrological regimes are found. In

530 calm hydrological conditions, surface load shows enrichment patterns of partly anthropogenic

531 elements (Mo, Mn, Cu, Zn, Cd, As, Sb and Bi) adsorbed onto clay minerals, oxyhydroxides

532 and organic matter. The differentiation of suspended material is not observed at high water

533 stages when more detrital material is supplied and part of a bed load is re-suspended.

534 4. During low and medium water table, samplers at the Sava River proved to be a reasonably

535 good means of collecting representative time-integrated suspended material. However,

536 different chemical composition of shallow and deep-positioned sampler, induced by

537 hydrodynamic sorting, could be recognized. Somewhat problematic conditions can occur at

538 high flow rate due to partial loss of the clay fraction and variation of elemental composition,

539 particularly in human-impacted rivers. Therefore, using anthropogenic elements, mostly

540 bound to that fraction, to compare materials sampled in different periods, requires additional

541 caution. Moreover, changes in redox conditions and high biological activity in a summer

542 period can invoke additional modifications of the chemical composition of the material and

543 consequently distort the conclusion about the representativeness of the SPM. Hence, in

544 order to interpret geochemical and mineralogical data (time-integrated) in sediment source

545 modeling or assessing river sediment quality, these factors should be considered. 
550 This work was supported by the Croatian Science Foundation under the project 7555

551 (TRACESS) and bilateral Croatian-Slovenian MSES project. The authors are grateful to Dr.

552 Ivo Lučić for his support in the field during the sampling campaigns as well as Mr. Roman

553 Trček's help on finding an appropriate location for TIMS positioning in the Savinja River.

\section{5. References}

555 Aguilar-Hinojosa, Y., Meza-Figueroa, D., Villalba-Atondo, A. I., Encinas-Romero, M. A., 556 Valenzuela-García, J. L., Gómez-Álvarez, A., 2016. Mobility and bioavailability of metals in 557 stream sediments impacted by mining activities:the Jaralito and the Mexicana in Sonora, 558 Mexico. Water Air Soil Poll 227, 345.

559 Armiento, G., Bellatreccia, F., Cremisini, C., Ventura, G.D., Nardi, E., Pacifico, R., 2013.

560 Beryllium natural background concentration and mobility: a reappraisal examining the case of 561 high Be-bearing pyroclastic rocks. Environ Monit Assess 185, 559-572.

562 Audry, S., Schäfer, J., Blanc, G., Bossy, C., Lavaux, G., 2004. Anthropogenic components of 563 heavy metals ( $\mathrm{Cd}, \mathrm{Zn}, \mathrm{Cu}, \mathrm{Pb})$ budgets in the Lot-Garonne fluvial system (France). Appl 564 Geochem 19(5), 769-786.

565 Balistrieri, L.S., Murray, J.W., Paul, B., 1994. The geochemical cycling of trace elements in a 566 biogenic meromictic lake. Geochim Cosmochim Acta 58, 3993-4008.

567 Baran, A., Mierzwa-Hersztek, M., Gondek, K., Tarnawski, M., Szara, M., Gorczyca, O., 568 Koniarz, T., 2019. The influence of the quantity and quality of sediment organic matter on the 569 potential mobility and toxicity of trace elements in bottom sediment. Environ Geochem Hlth $570 \quad 41,2893-2910$.

571 Barth-Wirsching, U., Klammer, D., Kovic-Kralj, P., 1994. The formation of analcime from 572 laumontite in the Smrekovec volcanics. Environ. Earth Sci. (2010) 59:951-956 955123

573 Northwest Slovenia—an experimental approach. In: Weitkamp J, Karge HG, Pfeifer H, 
574 Hoelderich W (eds) Zeolites and related microporous materials: state of the art 1994, Stud 575 Surf Sci Catal 84: 299-305.

576 Bauer, S., Blomqvist, S., Ingri, J., 2017. Distribution of dissolved and particulate 577 molybdenum, vanadium, and tungsten in the Baltic Sea. Mar Chem 196, 135-147.

578 Boschi, V., Willenbring, J.K., 2016. Beryllium desorption from minerals and organic ligands 579 over time. Chem Geol 439, 52-58.

580 Bouchez, J., Gaillardet, J., France-Lanord, C., Maurice, L., Dutra-Maia, P., 2011. Grain size 581 control of river suspended sediment geochemistry: clues from Amazon River depth profiles. 582 Geochem Geophy Geosy 12:Q03008.

583 Calvert, S.E., Pedersen, T.F., 1996. Sedimentary geochemistry of manganese: implications 584 for the environment of formation of manganiferous black shales. Econ Geol 91, 36-47.

585 Cerar, S. Urbanc, J., 2013. Carbonate Chemistry and Isotope Characteristics of Groundwater 586 of Ljubljansko Polje and Ljubljansko Barje Aquifers in Slovenia. Sci World J 2013, 1-11.

587 Chen, J.B., Gaillardet, J., Bouchez, J., Louvat, P., Wang, Y.N., 2014. Anthropophile elements 588 in river sediments: overview from the Seine River, France. Geochem Geophy Geosy 589 15:4526-4546.

590 Droppo, I.G., di Cenzo, P., Parrott, J., Power, J., 2019. The alberta oil sands eroded 591 bitumen/sediment transitional journey: influence on sediment transport dynamics, pah 592 signatures and toxicological effect. Sci Total Environ. 677, 718-731.

593 Droppo, I.G., Ongley, E.D., 1994. Flocculation of suspended sediment in rivers of south594 eastern Canada. Water. Res 28, 1799-1809.

595 European Communities Environmental Objectives (Surface Waters), 2009. Regulations S.I. 596 No. 272/2009. 
598 Fiket, Ž., Mikac, N., Kniewald, G., 2017. Mass fractions of forty-six major and trace elements, 599 including rare earth elements, in sediment and soil reference materials used in environmental 600 studies. Geostand Geoanal Res 41, 123-135.

601 Gaillardet, J., Viers, J., Dupre, B., 2003. Trace elements in river waters. In: James I. Drever 602 (Ed.). Holland, H.D., Turekian, K.K. (Executive Editors), Treatise on Geochemistry vol 5: 603 Surface and Ground Water, Weathering, and Soils. Elsevier, 225-272.

604 Galović, L., Peh, Z., 2014. Eolian contribution to geochemical and mineralogical 605 characteristics of some soil types in Medvednica Mountain, Croatia. Catena 117, 145-156.

606 Garçon, M., Chauvel, C., France-Lanord, C., Limonta, M., Garzanti, E., 2014. Which minerals 607 control the $\mathrm{Nd}-\mathrm{Hf}-\mathrm{Sr}-\mathrm{Pb}$ isotopic compositions of river sediments? Chem Geol 364, 42-55.

608 Garzanti, E., Andò, S., 2019. Heavy Minerals for Junior Woodchucks. Minerals 9, 148. 609 https://doi.org/10.3390/min9030148.

610 Garzanti, E., Ando, S., France-Lanord, C., Censi, P., Vignola, P., Galy, V., Lupker, M., 2011.

611 Mineralogical and chemical variability of fluvial sediments 2. Suspended-load silt (Ganga-

612 Brahmaputra, Bangladesh). Earth Planet Sci Lett 302, 107-120.

613 Garzanti, E., Andò, S., France-Lanord, C., Vezzoli, G., Galy, V., Najman, Y., 2010.

614 Mineralogical and chemical variability of fluvial sediments. 1. Bedload sand (Ganga615 Brahmaputra, Bangladesh). Earth Planet Sci Lett 299, 368-381.

616 Garzanti, E., Andò, S., Vezzoli, G., 2009. Grain-size dependence of sediment composition 617 and environmental bias in provenance studies. Earth Planet Sci Lett 277(3-4), 422-432.

618 Garzanti, E., Padoan, M., Andò, S., Resentini, A., Vezzoli, G., Lustrino, M., 2013. Weathering 619 and relative durability of detrital minerals in equatorial climate: sand petrology and 620 geochemistry in the East African Rift. J Geol 121, 547-580.

621 Gippel, C.J., 1995. Potential of turbidity monitoring for measuring the transport of suspended 622 solids in streams. Hydrol Process 9(1), 83-97. 
623 Goharrokhi, M., Pahlavan, M., Lobb, D.A., Owens, P.N., Clark, S.P., 2019. Assessing issues 624 associated with a time-integrated fluvial fine sediment sampler. Hydrol Process 33, 15, 20486252056.

626 Gottler, R.A., 2012. Part 3000 metals. In: Rice, E.W., Braid, R.B., Eaton, A.D., Clesce, L.S. 627 (Eds.), Standard Methods for the Examination of Water and Waste Water, 22nd ed. Port City 628 Press, Baltimore, MD, USA pp. 3-1-3-11.

629 Gregory, J., 2006. Particles in Water: Properties and Processes. IWA Publishing/CRC. 630 Press, London, U.K.

631 Hill, D.M., Aplin, A.C., 2001. Role of colloids and fine particles in the transport of metals in 632 rivers draining carbonate and silicate terrains. Limnol Oceanogr 46(2), 331-344.

633 Hinterlechner-Ravnik, A., Pleničar, M., 1967. Smrekovški andezit in njegov tuf (The 634 Smrekovec andesite and its tuff - in Slovenian). Geologija 10, 219-237.

635 Horowitz, A.J., 1991. A Primer in Sediment-trace Element Chemistry. Lewis Publishers, 636 Chelsea, MA, USA.

637 Horowitz, A.J., Elrick, K.A., 1987. The relation of stream sediment surface area, grain size 638 and composition to trace element chemistry. Appl Geochem 2, (4), 437-451.

639 Kahle, M., Kleber, M., Jahn, R., 2002. Review of XRD-based quantitative analyses of clay 640 minerals in soils: the suitability of mineral intensity factors. Geoderma 109, 191-205.

641 Kobold, M., Sušelj, K., 2005. Precipitation forecasts and their uncertainty as input into 642 hydrological models. Hydrol Earth Syst Sci 9, 322-332.

643 Kynčlová, P., Hron, K., Filzmoser, P., 2017. Correlation between compositional parts based 644 on symmetric balances. Math Geosci 49, 777-796.

645 Lerouge, C., David, K., Claret, F., Debure, M., Grangeon, S., Madé, B., Montavon, G., 646 Tournassata, C., 2017. Role of carbonate minerals in the distribution of trace elements in 647 marine clay formations. Procedia Earth Planet Sci 17, 798-801. 
Lučić, M., Jurina, I., Ščančar, J. Mikac, N., Vdović, N., 2019. Sedimentological and

649 geochemical characterization of river suspended particulate matter (SPM) sampled by time-

650 integrated mass flux sampler (TIMS) in the Sava River (Croatia). J Soils Sediments 19, 989-

6511004.

652 Martínez-Carreras, N., Krein, A., Gallart, F., Iffly, J.F., Hissler, C., Pfister, L., Hoffmann, L.,

653 Owens, P.N., 2012. The Influence of Sediment Sources and Hydrologic Events on the

654 Nutrient and Metal Content of Fine-Grained Sediments (Attert River Basin, Luxembourg).

655 Water Air Soil Poll 223, 5685-5705.

656 Marttila, H., Saarinen, T., Celebi, A., Kløve, B., 2013. Transport of particle-associated

657 elements in two agriculture-dominated boreal river systems. Sci Total Environ 461-462:693658705.

659 McDonald, D.M., Lamoureux, S.F., Warburton, J., 2010. Assessment of a time-integrated

660 fluvial suspended sediment sampler in a high arctic setting. Geogr Ann A, 92A:225-235.

661 Milačič, R., Zuliani, T., Vidmar, J., Oprčkal, P., Ščančar, J., 2017. Potentially toxic elements 662 in water and sediments of the Sava River under extreme flow events. Sci Total Environ 605$663606,894-905$.

664 Moore, D., Reynolds, R., 1997. X-Ray-Diffraction and the identification and analysis of clay 665 minerals. Oxford University Press, New York.

666 Morehead, M.D., Syvitski, J.P., Hutton, E.W.H., Peckham, S.D., 2003. Modeling the temporal 667 variability in the flux of sediment from ungauged river basins. Global Planet Change 39(1-2), $66895-110$.

669 Morford, J.L., 2019. Redox-Sensitive Metals. in: Encyclopedia of Ocean Sciences 3rd 670 Edition, edited by: Cochran, J.K., Bokuniewicz, H.J., Yager, P.L. Elsevier/Academic Press, $671323-327$. 
672 Ollivier, P., Radakovitch, O., Hamelin, B., 2011. Major and trace partition and fluxes in the 673 Rhône River. Chem Geol 285, 15-31.

674 Pawlowsky-Glahn, V., Egozcue, J. J., Tolosana-Delgado, R., 2015. Modeling and Analysis of 675 Compositional Data. London: John Wiley \& Sons.

676 Perks, M.T., Warburton, J., Bracken, L., 2014. Critical assessment and validation of a time677 integrating fluvial suspended sediment sampler. Hydrol Process 28(17), 4795-4807.

678 Phillips, J.M., Russel, M.A., Walling, D.E., 2000. Time-integrated sampling of fluvial 679 suspended sediment: a simple methodology for small catchments. Hydrol Process 14, 25896802602.

681 Placer, L., 2008. Principles of the tectonic subdivision of Slovenia. Geologija, 51/2, 205-217.

682 Quinn, K.A., Byrne, R.H., Schijf, J., 2006. Sorption of yttrium and rare earth elements by 683 amorphous ferric hydroxide: influence of $\mathrm{pH}$ and ionic strength. Mar Chem 99, 128-150.

684 R core team, 2017. R: a language and environment for statistical computing. R Foundation 685 for statistical computing, Vienna, Austria URL http://www.R-project.org.

686 Rambeau, C.M.C., Baize, D., Saby, N.P.A., Matera, V., Adatte, T., Foellmi, K.B., 2010. High 687 Cadmium concentrations in Jurassic limestone as the cause for elevated cadmium levels in 688 deriving soils: a case study in Lower Burgundy, France. Environ Earth Sci 61, 1573-585.

689 Reimann, C., Filzmoser, P., Fabian, K., Hron, K., Birke, M., Demetriades, A., 2012. The 690 concept of compositional data analysis in practice - total major element concentrations in 691 agricultural and grazing land soils of Europe. Sci Total Environ 426, 196-210.

692 Reimann, C., Filzmoser, P., Hron, K., Kynčlová, P., Garrett, R.G., 2017. A new method for 693 correlation analysis of compositional (environmental) data - a worked example Sci Total 694 Environ 607-608, 965-971. 
695

696

697

698

699

700

701

702

703

704

705

706

707

708

709

710

711

712

713

714

715

716

717 Šikić, K., Basch, O, Šimunić, A., 1979. Geological Map of SFRJ in scale 1:100000.

718 Explanatory booklet to sheet Zagreb.- Federal Geological Survey, Beograd. 
719 Tribovillard, N., Algeo, T., Lyons, T.W., Riboulleau, A., 2006. Trace metals as paleoredox

720 and paleoproductivity proxies: an update. Chem Geol 232, 12-32.

721 Tuna, G.S., Braida, W., Ogundipe, A., Strickland, D., 2012. Assessing tungsten transport in

722 thevadose zone: From dissolution studies to soil columns. Chemosphere 86, 1001-1007.

723 Vidmar, J., Zuliani, T., Novak, P., Drinčić, A., Ščančar, J., Milačič, R., 2016. Elements in 724 water, suspended particulate matter and sediments of the Sava River. J Soils Sediments $725 \quad 17: 1917-1927$.

726 Viers, J., Dupré, B., Gaillardet, J., 2009. Chemical composition of suspended sediments in

727 World Rivers: New insights from a new database. Sci Total Environ 407, 853-868.

728 Viers, J., Roddaz, M., Filizola, N., Guyot, J.L., Sondag, F., Brunet, P., Zouiten, C.,

729 Boucayrand, C., Martin, F., Boaventura, G.R., 2008. Seasonal and provenance controls on

$730 \mathrm{Nd}-\mathrm{Sr}$ isotopic compositions of Amazon rivers suspended sediments and implications for $\mathrm{Nd}$ 731 and Sr fluxes exported to the Atlantic Ocean, Earth Planet Sci Lett 274, 511-523.

732 Walling, D.E., Owens, P.N., Waterfall, B.D., Leeks, G.J., Wass, P. D., 2000. The particle size 733 characteristics of fluvial suspended sediment in the Humber and Tweed catchments, UK. Sci 734 Total Environ, 251-252, 205-222.

735 Woodward, J., Walling, D.E., 2007. Composite suspended sediment particles in river 736 systems: their incidence, dynamics and physical characteristics. Hydrol Process 21, 36017373614.

738 Wu, W., Zheng, H., Xu, S., Yang, J., Liu, W., 2013. Trace element geochemistry of riverbed 739 and suspended sediments in the upper Yangtze River. J Geochem Explor 124, 67-78. 
Figure 1. Map of sampling sites (map sourced from https://maps-for-free.com/).

Figure 2. Water discharge, suspended particulate matter (SPM) concentrations and timing of collecting single-point SPM samples at the Zagreb sampling site during five sampling campaigns (October and November 2016; February, April and July 2017). Data provided from Meteorological and Hydrological Service.

Figure 3. Heat-maps of correlation coefficients based on symmetric coordinates for different types of samples; A) TIMS, B) single-point SPM and C) fine-grained sediments. Samples from all locations are included.

Figure 4. Doubly-normalized chemical composition of the fine-grained sediment and singlepoint SPM from the Sava River, Zagreb. SPM average refers to at least four single-point SPM samples. The samples are normalized to TIMS: A) first sampling campaign (October 2016);

B) second sampling campaign (November 2016);

C) third sampling campaign (February 2017);

D) fourth sampling campaign (April 2017); E)

E) fifth sampling campaign (July 2017). The elements are arranged following the periodic table groups.

Figure 5. Doubly-normalized chemical composition of fine-grained sediment and single-point SPM from the Sava River, Radovljica. The samples are normalized to TIMS: SRAD1 - first sampling campaign (October), SRAD2 - second sampling campaign (November). The elements are arranged following the periodic table groups.

Figure 6. Doubly-normalized chemical composition of fine-grained sediment and single-point SPM at the tributaries. The samples are normalized to TIMS: A) the Ljubljanica River (Podgrad); B) the Savinja River (Veliko Širje; C) the Krapina River (Zaprešić). The elements are arranged following the periodic table groups. 


\section{Declaration of interests}

$\bigotimes$ The authors declare that they have no known competing financial interests or personal relationships that could have appeared to influence the work reported in this paper.

$\square$ The authors declare the following financial interests/personal relationships which may be considered as potential competing interests:

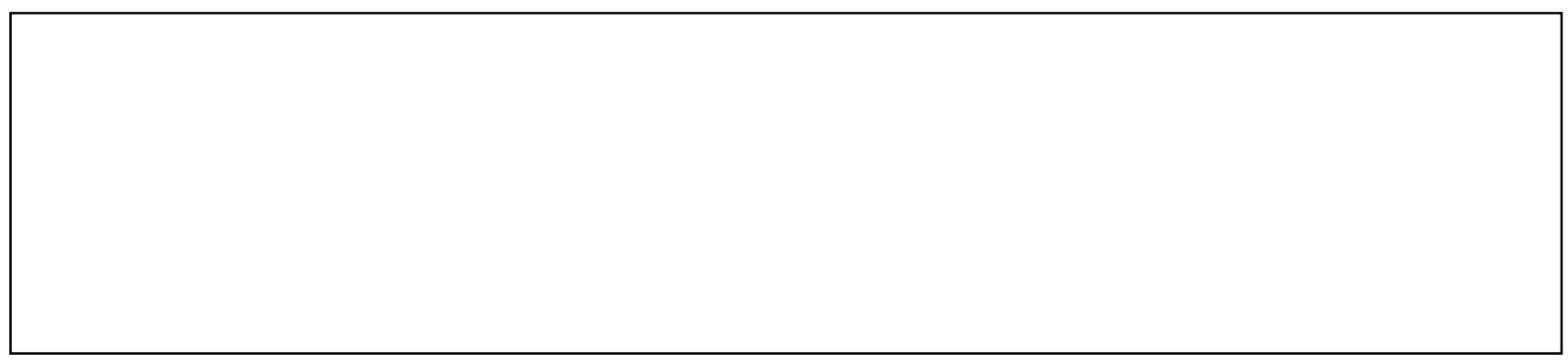




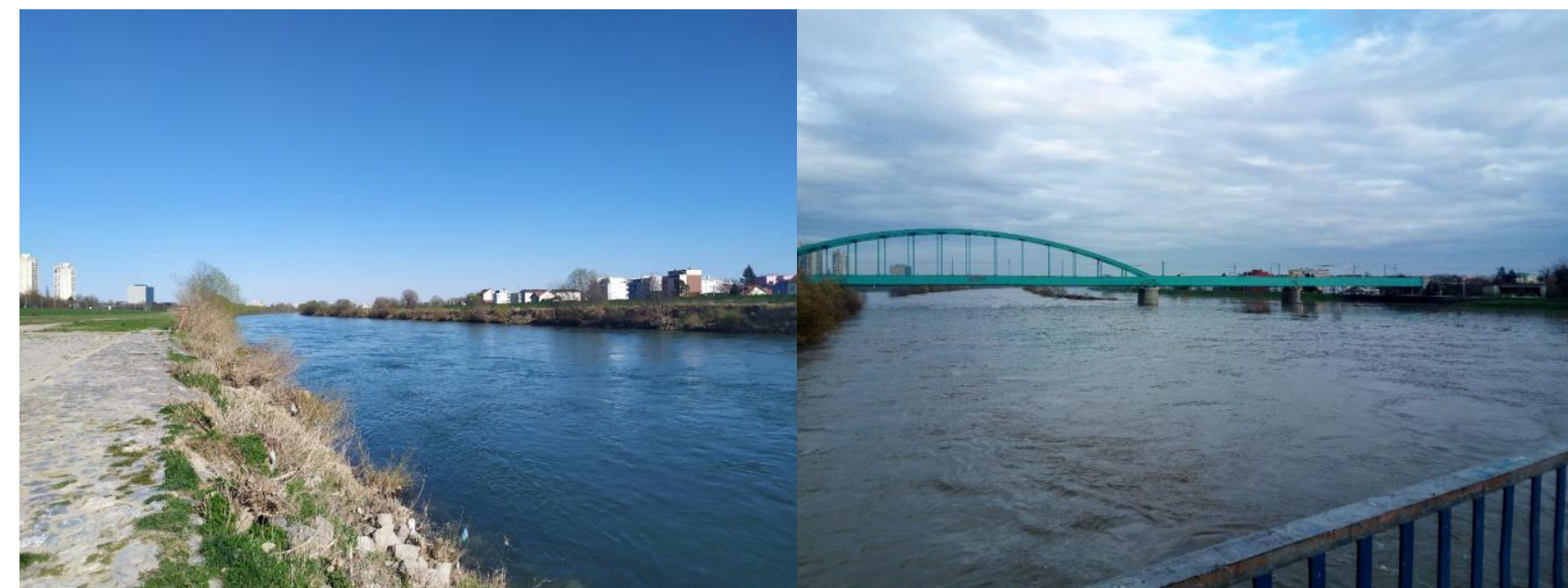

Good representativeness of SPM collected by TIMS

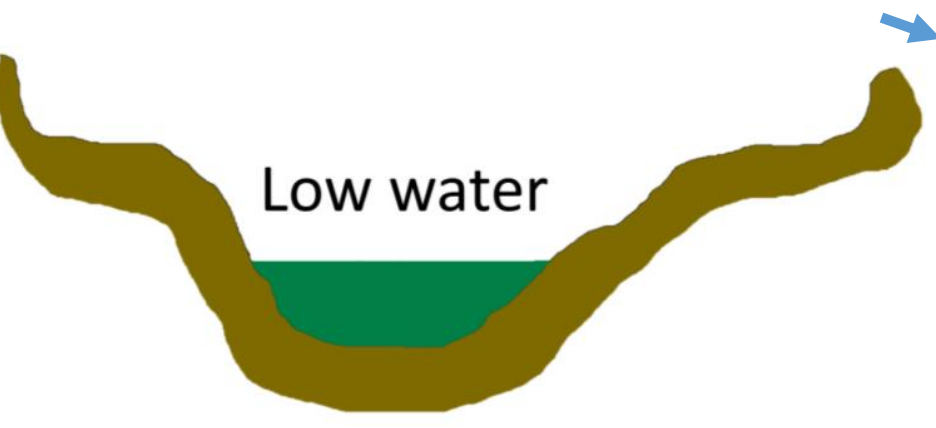

SPM is abundant in clay minerals, oxyhydroxides and organic matter
Lower capability to retain clay-rich particles in TIMS

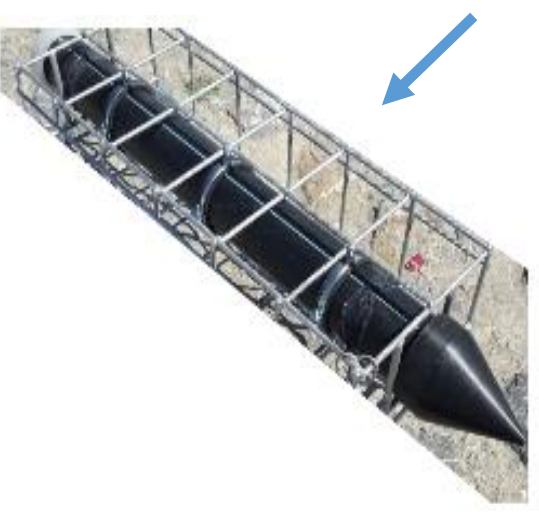

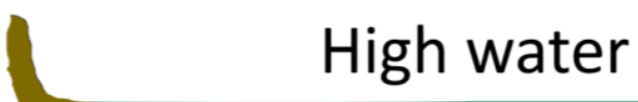

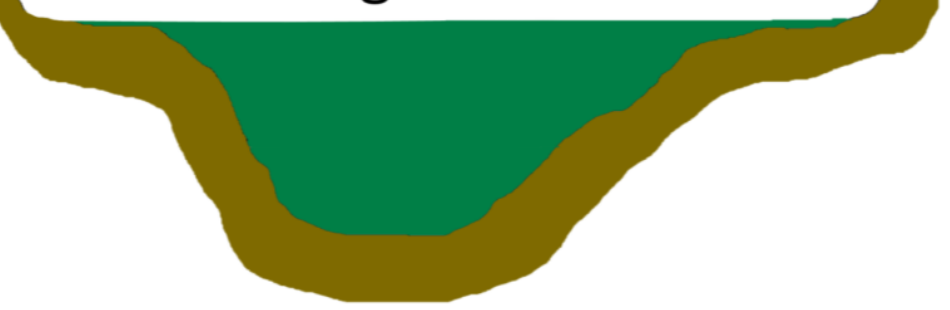

Part of bed load is also re-suspended Homogenization takes place

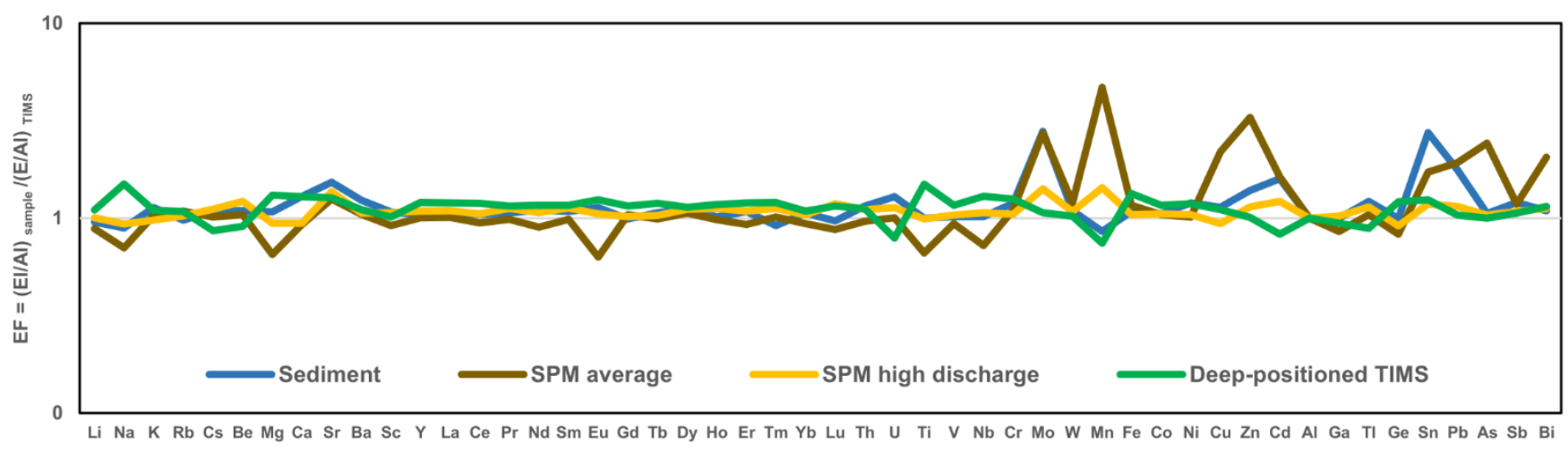


Supplementary material for on-line publication only
Click here to download Supplementary material for on-line publication only: Lucic et al Appendix A.docx

Supplementary material for on-line publication only
Click here to download Supplementary material for on-line publication only: Lucic et al Appendix A.docx

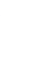

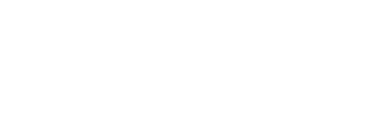
. (1) (1) (1) (1) (1) (1) (1) (1) (1) (1) 

Supplementary material for on-line publication only
Click here to download Supplementary material for o Click here to download Supplementary material for on-line publication only: Lucic et al Appendix B.xIsx 
Click here to download high resolution image

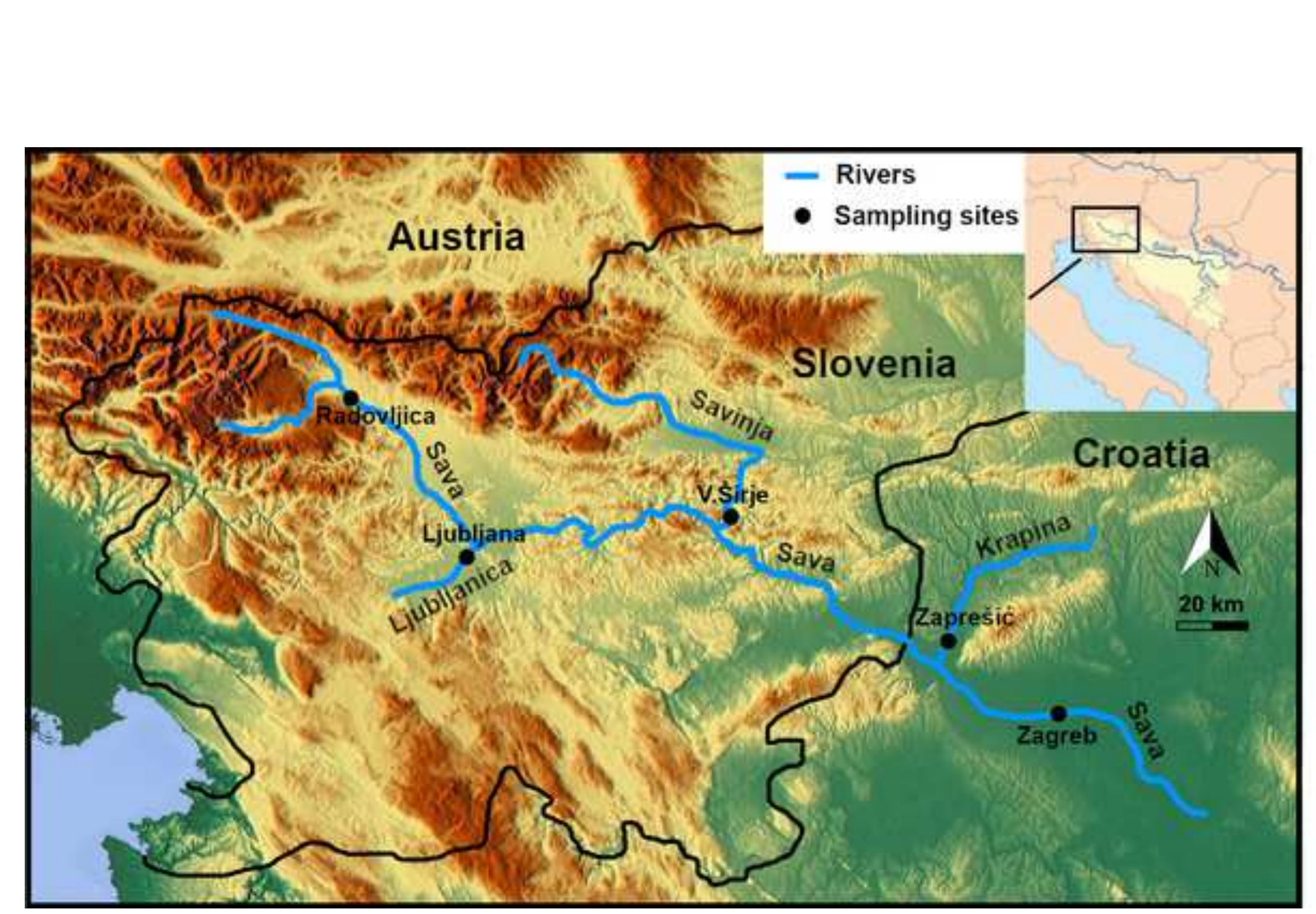




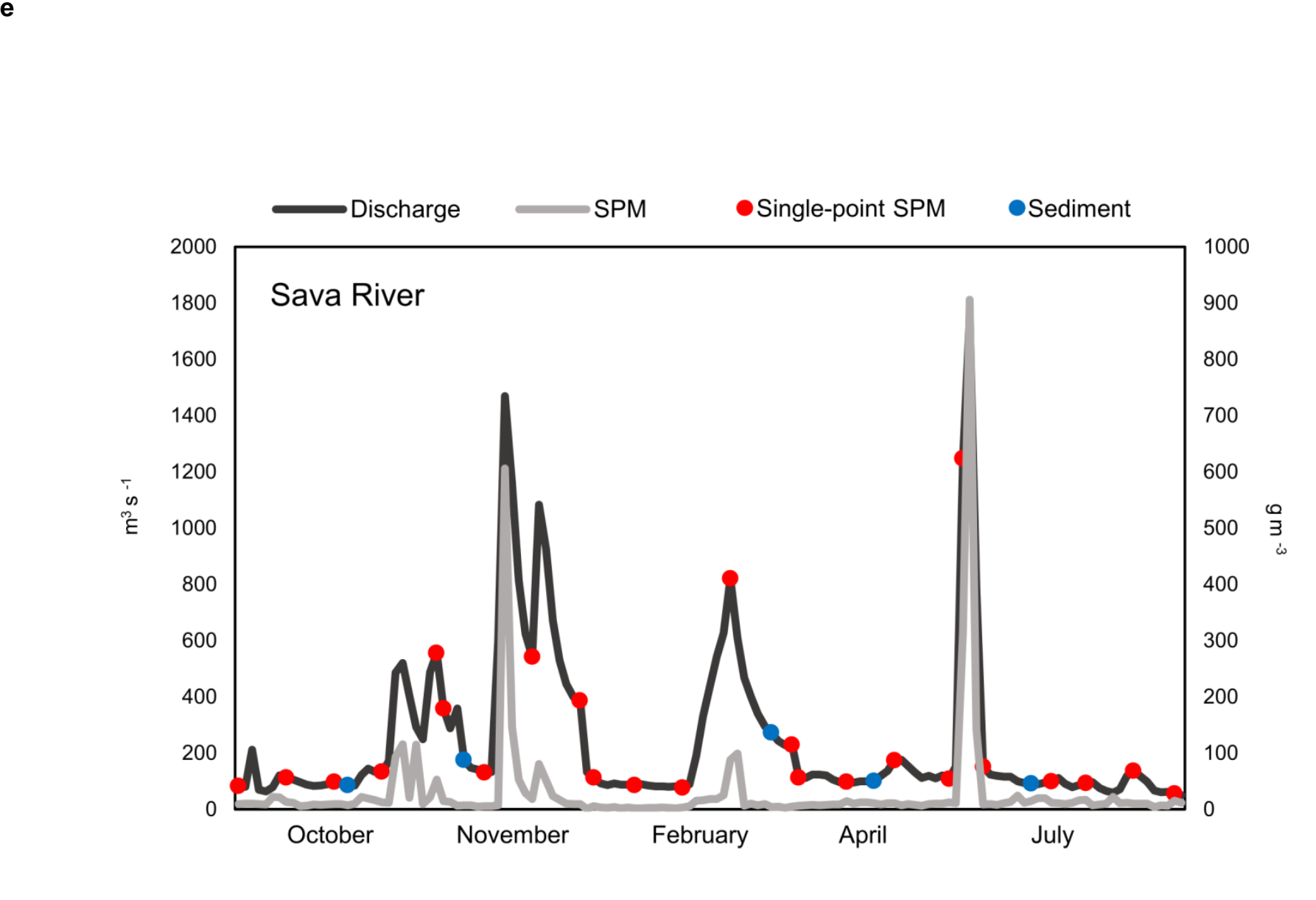

Figure

Eigure

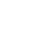




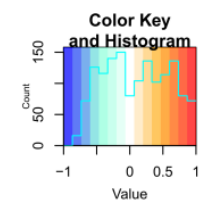

A) TIMS
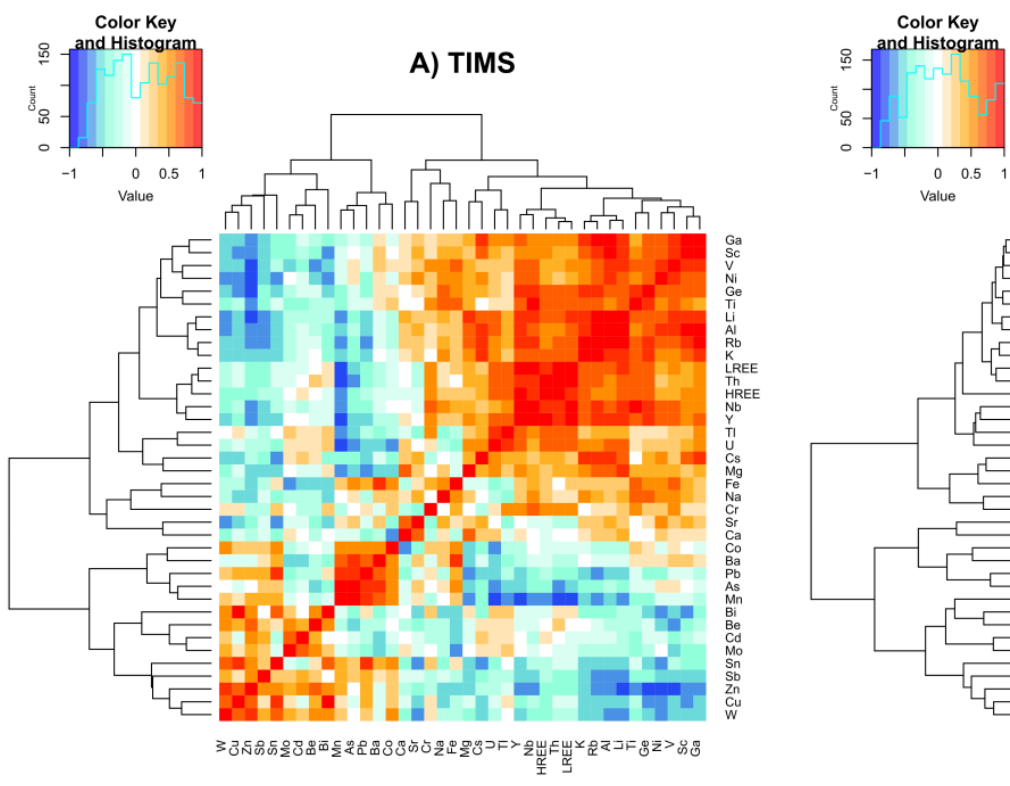

B) Single-point SPM
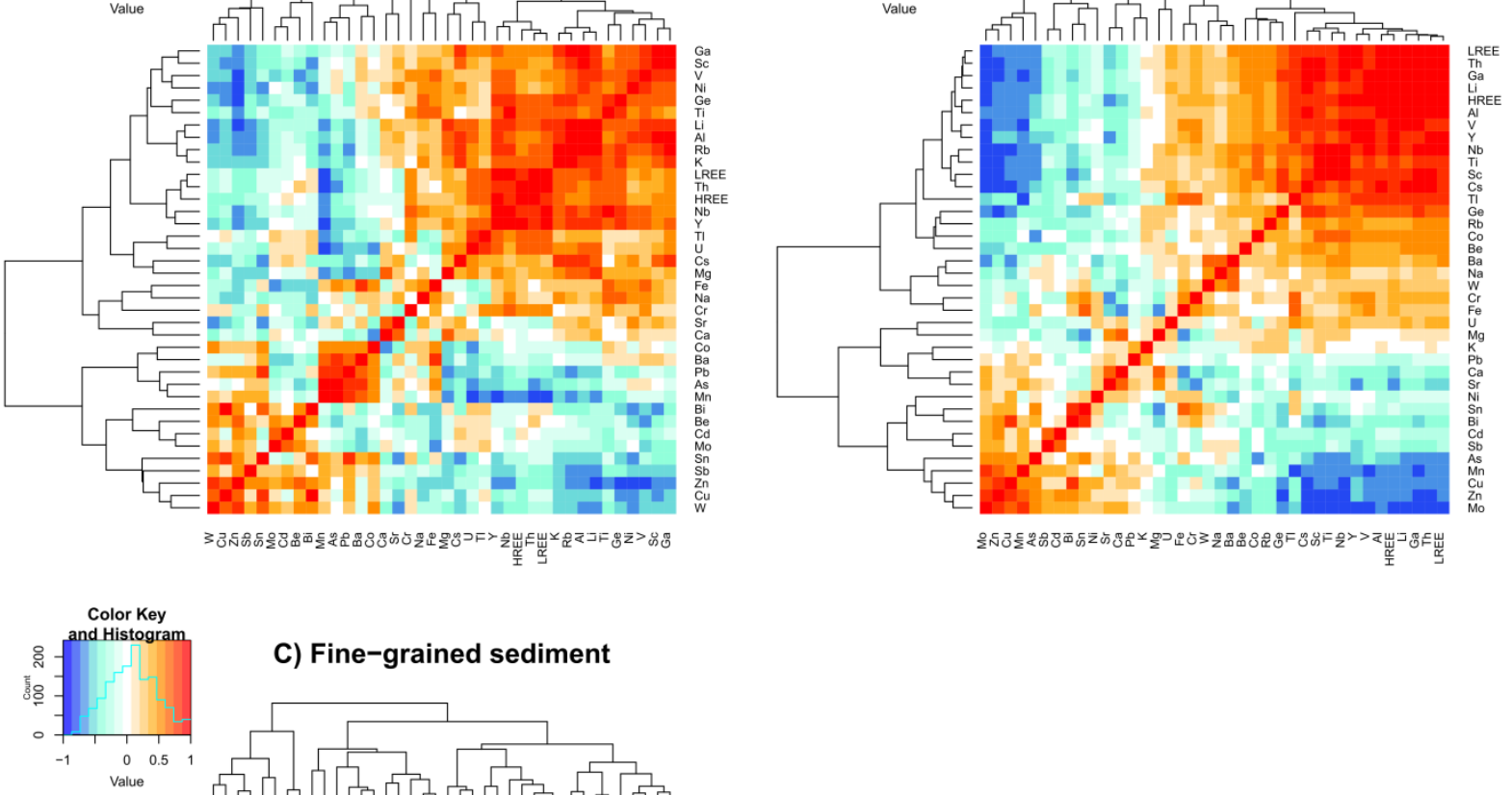

C) Fine-grained sediment

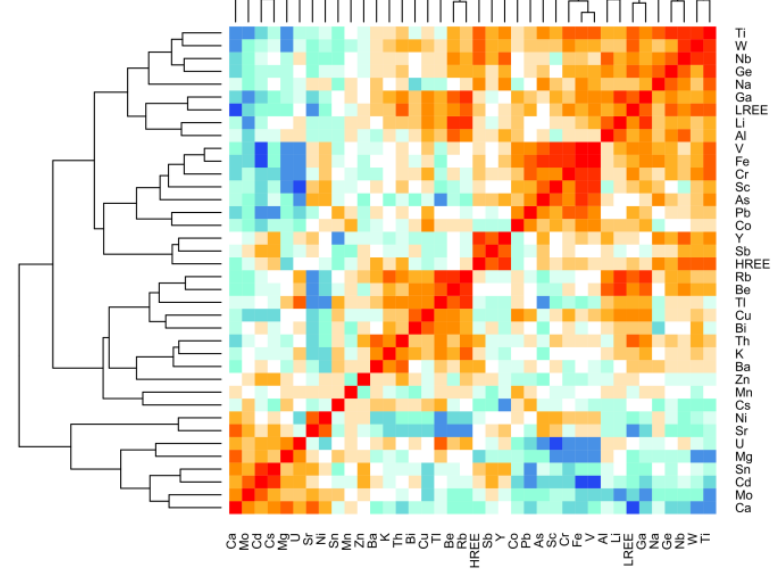



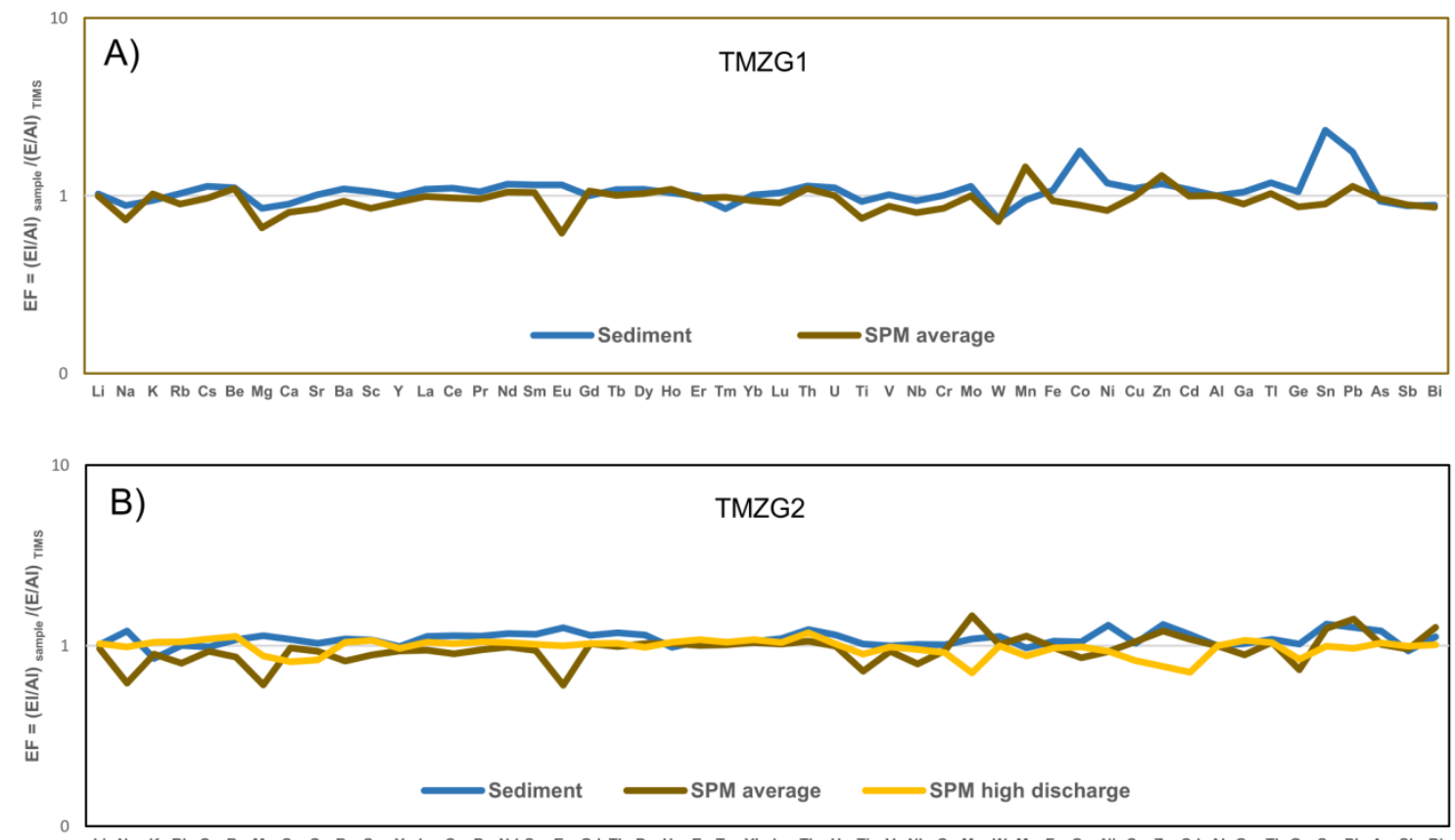

Li Na K Rb Cs Be Mg Ca Sr Ba Sc Y La Ce Pr Nd Sm Eu Gd Tb Dy Ho Er Tm Yb Lu Th U Ti V Nb Cr Mo W Mn Fe Co Ni Cu Zn Cd Al Ga Tl Ge Sn Pb As Sb Bi
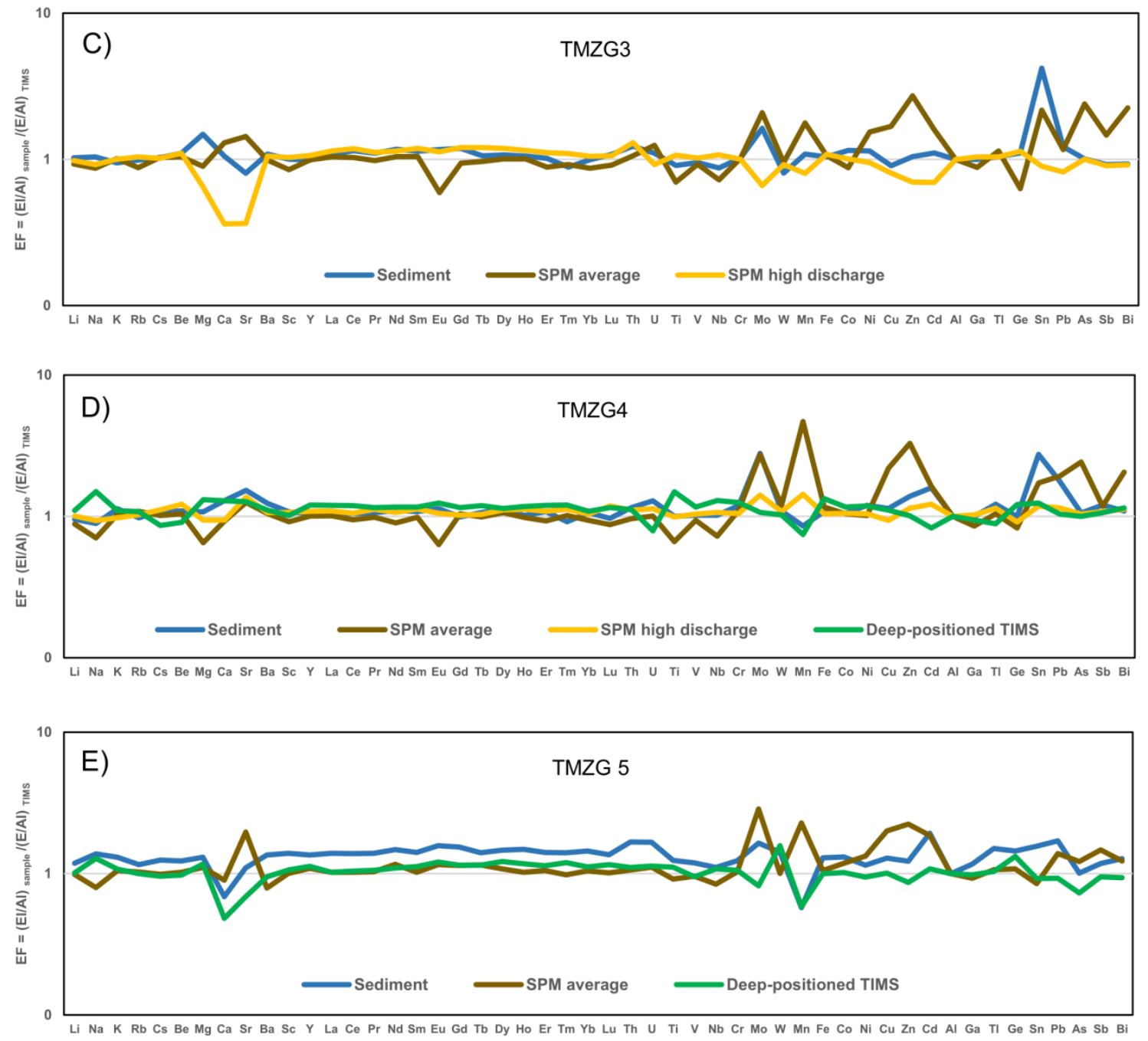


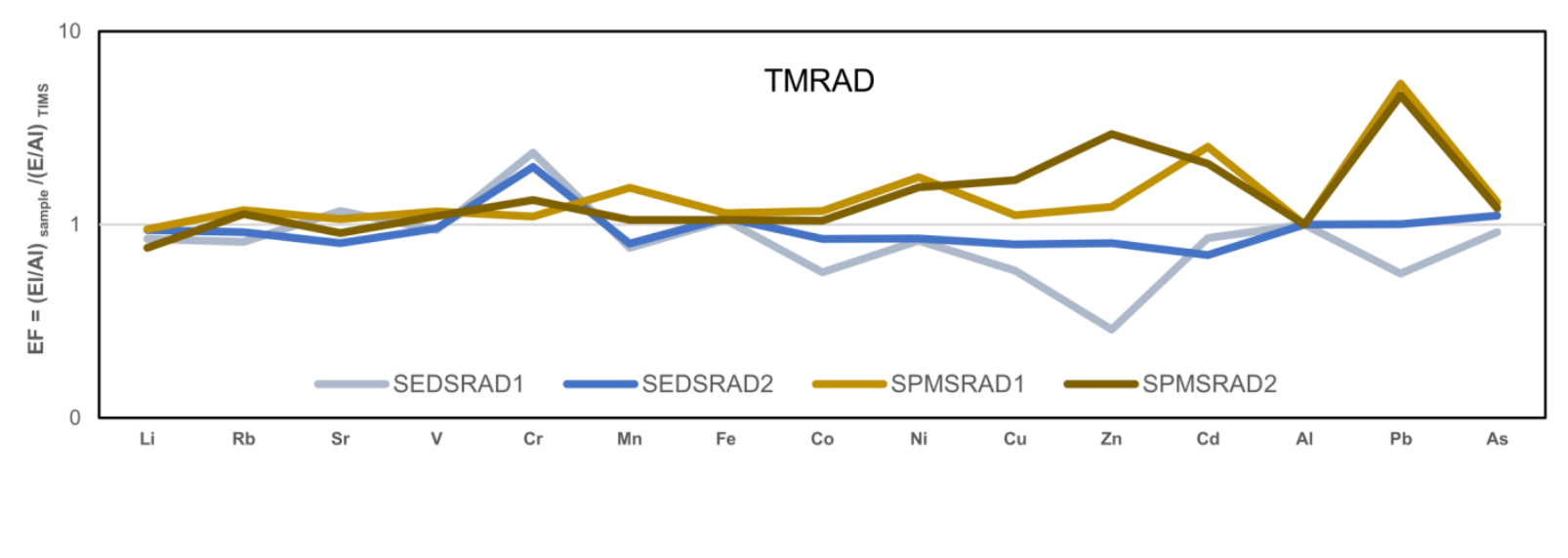

Figure
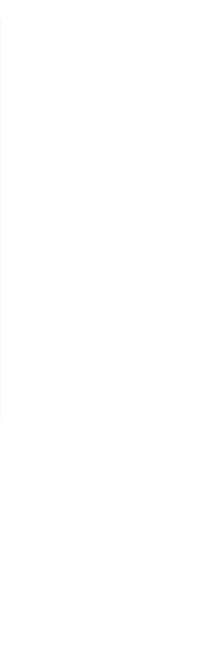

.

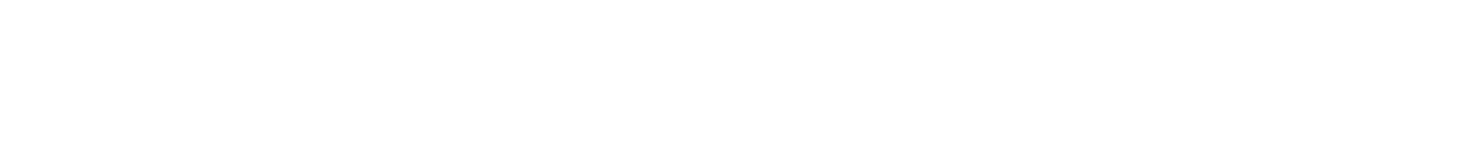



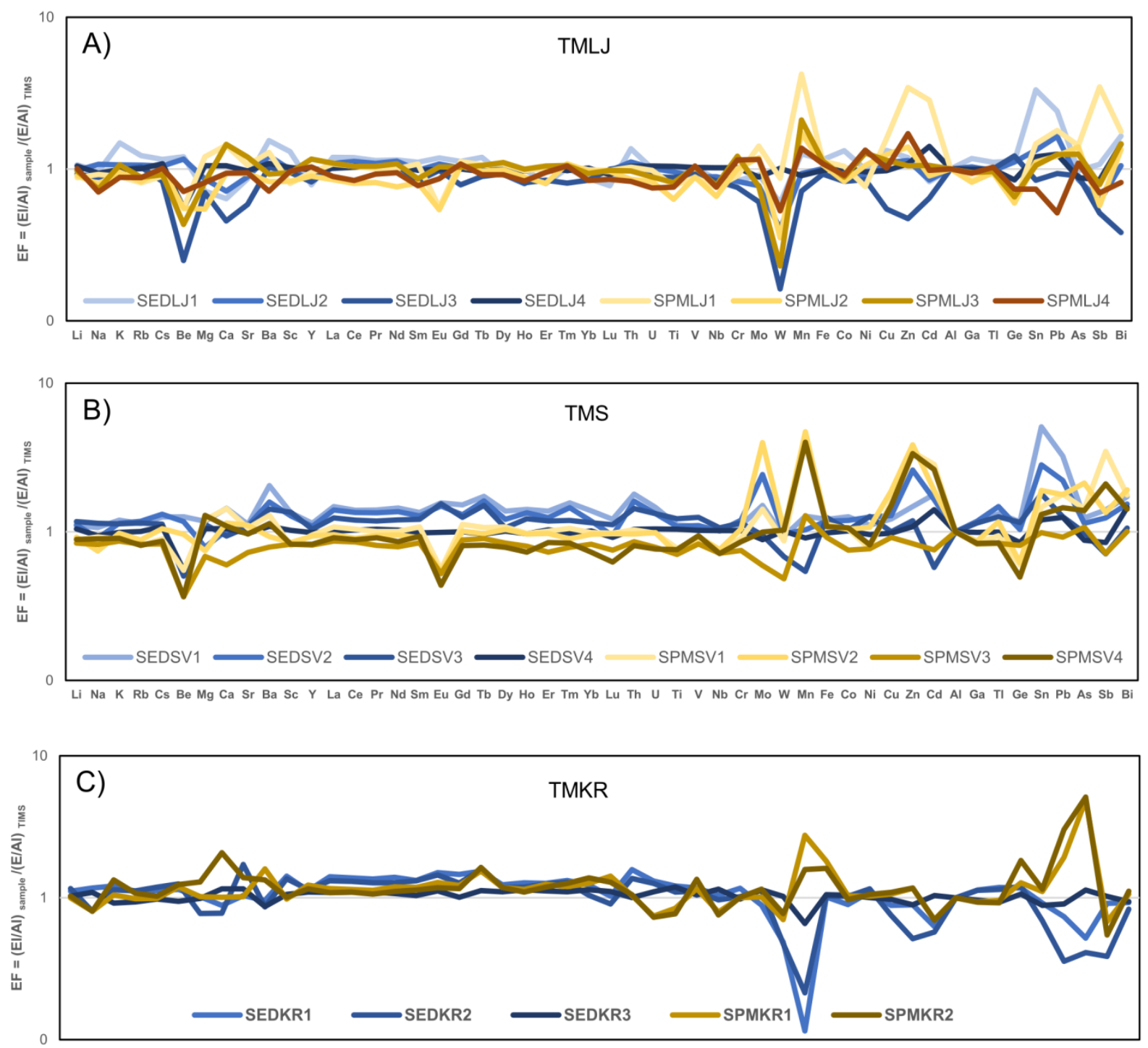

Li Na K Rb Cs Be Mg Ca Sr Ba Sc Y La Ce Pr Nd Sm Eu Gd Tb Dy Ho Er Tm Yb Lu Th U Ti V Nb Cr Mo W Mn Fe Co Ni Cu Zn Cd Al Ga Tl Ge Sn Pb As Sb Bi 